\title{
"Re-educating" Tumor Associated Macrophages as a Novel Immunotherapy Strategy for Neuroblastoma
}

\begin{abstract}
Kevin X. Liu ${ }^{1,2}$ and Shweta Joshi ${ }^{3 *}$
${ }^{1}$ Department of Radiation Oncology, Brigham and Women's Hospital, Harvard Medical School, Boston, MA, United States, 2 Department of Radiation Oncology, Dana-Farber Cancer Institute, Boston Children's Hospital, Harvard Medical School, Boston, MA, United States, ${ }^{3}$ Division of Pediatric Hematology-Oncology, Department of Pediatrics, UCSD Rady's Children's Hospital, University of California, San Diego, La Jolla, CA, United States
\end{abstract}

Neuroblastoma is the most common extracranial pediatric tumor and often presents with metastatic disease, and patients with high-risk neuroblastoma have survival rates of $\sim 50 \%$. Neuroblastoma tumorigenesis is associated with the infiltration of various types of immune cells, including myeloid derived suppressor cells, tumor associated macrophages (TAMs), and regulatory T cells, which foster tumor growth and harbor immunosuppressive functions. In particular, TAMs predict poor clinical outcomes

OPEN ACCESS

Edited by:

Maciej M. Markiewski,

Texas Tech University Health Sciences

Center, United States

Reviewed by:

Peter Keyel,

Texas Tech University, United States

Stefano Ugel,

University of Verona, Italy

*Correspondence:

Shweta Joshi

shjoshi@health.ucsd.edu

Specialty section:

This article was submitted to

Cancer Immunity and Immunotherapy,

a section of the journal

Frontiers in Immunology

Received: 01 May 2020

Accepted: 20 July 2020

Published: 02 September 2020

Citation:

Liu KX and Joshi S (2020)

"Re-educating" Tumor Associated

Macrophages as a Novel

Immunotherapy Strategy for

Neuroblastoma.

Front. Immunol. 11:1947.

doi: 10.3389/fimmu.2020.01947 in neuroblastoma, and among these immune cells, TAMs with an M2 phenotype comprise an immune cell population that promotes tumor metastasis, contributes to immunosuppression, and leads to failure of radiation or checkpoint inhibitor therapy. This review article summarizes the role of macrophages in tumor angiogenesis, metastasis, and immunosuppression in neuroblastoma and discusses the recent advances in "macrophage-targeting strategies" in neuroblastoma with a focus on three aspects: (1) inhibition of macrophage recruitment, (2) targeting macrophage survival, and (3) reprogramming of macrophages into an immunostimulatory phenotype.

\section{Keywords: tumor associated macrophage, neuroblastoma, immunosuppression, polarization, metastasis}

\section{INTRODUCTION}

Accounting for more than $15 \%$ of all childhood cancer deaths, neuroblastoma is a malignant pediatric cancer arising from neural crest cells of the sympathetic nervous system $(1,2)$. Risk stratification for patients with neuroblastoma have evolved over time, and currently utilize the International Neuroblastoma Risk Group consensus criteria, which includes age at diagnosis, disease stage, tumor pathologic features, including histology and tumor cell ploidy, and tumor genetic characteristics, such as MYCN amplification and chromosomal aberrations (3-6). In particular, MYCN is an oncogenic driver, and MYCN amplification is found in $\sim 40-50 \%$ of high-risk neuroblastoma and associated with poor outcomes (7-10).

Treatment regimens for neuroblastoma vary depending on the patient's risk classification. Patients who are diagnosed with very low or low risk neuroblastoma can achieve $>90 \% 5$-year overall survival (OS) even after resection alone or observation for asymptomatic patients $(3,5,11$, 12). With response-adjusted chemotherapy and resection, intermediate-risk patients have excellent survival rates of $>90 \%$ at 5 -years $(3,5,12,13)$. Approximately $40-50 \%$ of patients are diagnosed with high-risk disease, which requires multimodality treatment, including chemotherapy, surgery, 
myeloablative chemotherapy with autologous stem cell transplant, radiation therapy, and anti-disialoganglioside (GD2)based immunotherapy $(10,14-17)$. For patients with high-risk disease, 5-year OS remains $\sim 50 \%$ despite these aggressive strategies $(8,14,15)$. Hence, novel effective therapeutic avenues are needed to combat high-risk neuroblastoma.

Immunotherapy in the form of targeted antibodies has revolutionized the field of cancer therapy and is a promising approach to improve outcomes for patients with high-risk neuroblastoma (14). GD2 is a ganglioside that is expressed by neuroblastoma cells and serves as a target for monoclonal antibody (mAb)-based therapeutic intervention. Anti-GD2 $\mathrm{mAb}$ therapy is well-tolerated in patients with high-risk neuroblastoma, and a Phase III clinical trial found that the addition of anti-GD2 mAb, interleukin-2 (IL-2), granulocytemacrophage colony-stimulating factor (GM-CSF) to retinoic acid therapy significantly improved event-free survival (EFS) and OS in high-risk neuroblastoma (18-20). The importance of IL-2 and GM-CSF is unclear with a recent Phase III clinical trial demonstrating no additional benefit to subcutaneous IL-2 (21). Consolidative therapy with anti-GD2 mAb, such as dinutuximab, is now standard of care for patients with high-risk neuroblastoma. Recently, T cells have been engineered to express GD2 chimeric antigen receptor (CAR), and early-phase clinical trials using CAR-T cells for neuroblastoma show this therapy is safe and feasible with some promising results (22-24). However, due to the immunosuppressive tumor microenvironment and lack of tumor antigens (25-28), the approach with CAR-T cell therapy remains challenging in neuroblastoma compared to hematological malignancies. The monoclonal antibodies directed against inhibitory receptors on $\mathrm{T}$ cells, such as programmed cell death protein 1 (PD-1) and cytotoxic T-lymphocyte-associated protein 4 (CTLA-4), have shown great efficacy in many adult solid tumors $(29,30)$. However, in pediatric tumors, these checkpoint inhibitors have shown no significant benefit, which may be due to many factors, including the paucity of neoantigens, development of resistance, and an immunosuppressive environment unique to pediatric solid tumors (31-35). Studies have identified tumor associated macrophages (TAMs) within the immunosuppressive microenvironment of pediatric solid tumors, including neuroblastoma, play important roles in inhibiting both innate and adaptive immune responses (36-39). Hence, a better understanding of the immunosuppressive strategies utilized by macrophages to evade the immune system may help improve responses to immune-directed therapy in pediatric solid malignancies, including neuroblastoma. This review will discuss the neuroblastoma immunosuppressive microenvironment, mechanisms by which TAMs promote tumor progression and immunosuppression in neuroblastoma, and targeting of macrophages as a novel immunotherapy for neuroblastoma.

\section{TUMOR MICROENVIRONMENT OF NEUROBLASTOMA}

The tumor microenvironment in neuroblastoma is comprised of cancer associated fibroblasts (CAFs), mesenchymal stromal cells (MSCs), endothelial cells, and immune cells, all of which contribute to promoting a vascular, angiogenic, hypoxic and immunosuppressive milieu around the tumor cells $(36,40-$ 42). Various reports have shown that the microenvironment of neuroblastoma tumors has immunosuppressive components. Defects in antigen presenting machinery (APM) and low levels of MHC class I molecule displayed by neuroblastoma tumor cells lead to decreased cytotoxic T-cell activation and contributes to immunosuppression (43-49). Secretion of different soluble factors, such as transforming growth factor- $\beta$ (TGF- $\beta$ ), and galectin-1 by tumor cells, directly inhibit $\mathrm{T}$ cell function, leading to decreased tumor killing (50-52). The neuroblastoma tumor microenvironment also includes infiltration of various anti-inflammatory immune cells, which inhibits innate and adaptive immune responses and promotes tumor progression $(31,36)$. In this section, we will discuss the role of immune cells in mediating immunosuppressive microenvironment, and detailed descriptions regarding the role of CAFs, MSCs, and other components in promoting an immunosuppressive tumor microenvironment in neuroblastoma has been reviewed before $(36,40,42)$.

Diverse immune cell populations, including myeloid derived suppressor cells (MDSCs), TAMs, Cluster of differentiation (CD4) CD4+/CD8+ T cells, natural killer (NK) cells, and regulatory $\mathrm{T}$ cells (Treg), infiltrate neuroblastoma tumors, and through crosstalk, contribute to immunosuppression. Cancer associated fibroblasts (CAFs), immune cells and tumor cells secrete several cytokines to recruit TAMs and higher infiltration of TAMs in return modulate the functions of other immune cells leading to immunosuppressive microenvironment in neuroblastoma as reported before (36) and illustrated in Figure 1. Early in tumorigenesis, infiltration of cytotoxic CD8+ T cells often predominates; however, as the tumor progresses, the infiltration of TAMs, MDSCs and Treg cells, all of which mediate immunosuppression, increase in the tumor microenvironment $(53,54)$. In neuroblastoma, presence of cytotoxic CD8+ T cells, CD4+ Th1 cells and NK cells are prognostic factors of improved survival (55). Conversely, the presence of immunosuppressive cells like TAMs, MDSCs, and Treg correlate with poor clinical outcomes in neuroblastoma $(25,56)$. Importantly, tumor cells and immune cell populations function in concert and through crosstalk to facilitate immunosuppression to further promote tumor growth and metastasis.

In recent years, immune checkpoint blockade has demonstrated that targeting the immune system by activating previously exhausted or dysfunctional $\mathrm{T}$ cells can lead to longterm control of various cancers, including melanoma (57-59). In particular, cytotoxic CD8 $+\mathrm{T}$ cells are important for tumor cell killing and memory CD8 $+\mathrm{T}$ cells are important for durable anti-tumor immunity (60). However, many tumors, including neuroblastoma and other pediatric tumors, do not respond or have limited response to CTLA- 4 and PD-1/Programmed death-ligand 1 (PD-L1) blockade $(32,33)$, and studies have found mechanisms of resistance, including poor infiltration of $\mathrm{T}$ cells, tumor cells that lack response to interferon- $\gamma$ (IFN- $\gamma$ ), and immunosuppressive cell populations in the tumor microenvironment (61). Research has identified many different immune checkpoint receptors and ligands that regulate 


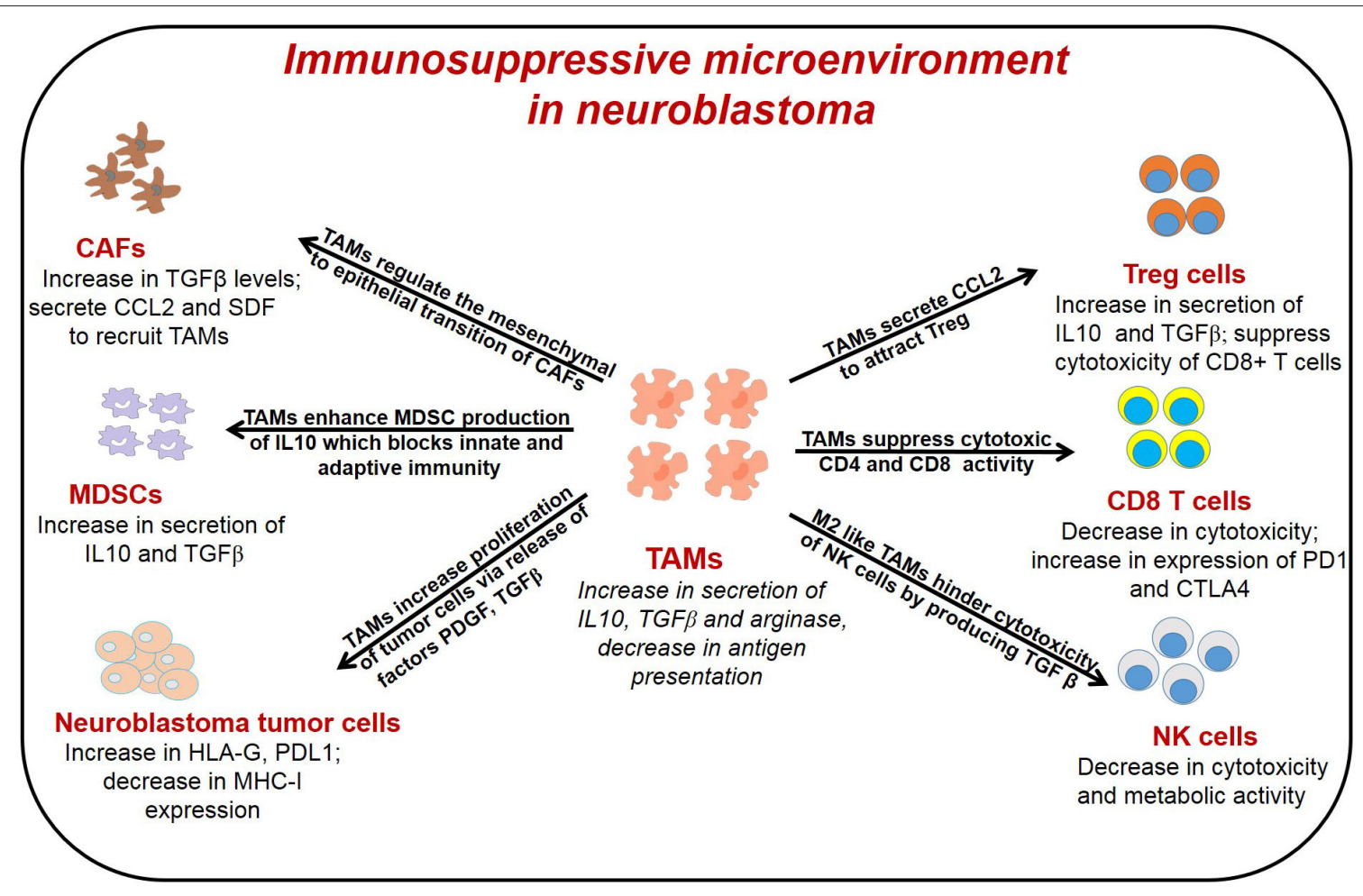

FIGURE 1 | General representation of different immune cells in the TME of neuroblastoma and their interaction with TAMs. TAMs interact with different immune cells to promote tumor angiogenesis, immunosuppression and metastasis. TAMs, tumor associated macrophages; CAFs, cancer associated fibroblast; $T$ reg, regulatory $T$ cells; MDSCs, myeloid derived suppressor cells; NK cells, natural killer cells.

T-cell function through antigen-presenting cells, and thus, there is growing interest to understand the interactions within the tumor microenvironment between tumor cells, antigenpresenting cells, and T-cells, particularly the contribution of the immunosuppressive tumor microenvironment to tumorigenesis $(57,58)$.

Within tumors, some myeloid cells may not fully differentiate into dendritic cells, macrophages, or granulocytes, and instead generate a heterogeneous population of immature immunosuppressive myeloid cells, MDSCs $(62,63)$. In particular, in humans, MDSCs are commonly defined as CD14-CD11b+CD33+ cells that do not have cell-surface markers specific for terminal differentiated myeloid fates and lack expression of HLA-DR $(62,63)$. In mice, MDSCs are frequently defined by $\mathrm{CD} 11 \mathrm{~b}+\mathrm{Gr} 1+$; however, monocytic and granlocytic subtypes can be further defined by Ly6C high/Ly6Gand Ly6C $\mathrm{C}^{\text {low }} \mathrm{Ly} 6 \mathrm{G}+$ expression, corresponding to monocytic and granulocytic subtypes, respectively (62). Studies have found that both subtypes of MDSCs along with monocytes and neutrophils are recruited by chemokines, including $\mathrm{C}-\mathrm{C}$ Motif Chemokine Ligand 2 (CCL2), CCL7, and chemokine (C-X-C motif) ligand 1 (CXCL1), produced by tumor cells and TAMs in neuroblastoma and other tumors (64-67). After their recruitment to the tumor microenvironment, MDSCs play an important role in mediating immunosuppression by inhibiting the activity of $\mathrm{T}$ cells, NK cells, and dendritic cells through multiple mechanisms $(54,68,69)$. In addition to producing nitric oxide and reactive oxygen species, which directly affect $\mathrm{T}$ cell function, MDSCs can deplete L-arginine, a necessary factor for $\mathrm{T}$ cell proliferation (66). Moreover, MDSCs produce cytokines, including IL-10 and TGF- $\beta$, to induce Treg cells, and inhibit NK cell activation and cytotoxicity (66). Recent studies have also found that MDSCs inhibit dendritic cell differentiation, hinder migration of dendritic cells, and prevent activation of CD8+ $\mathrm{T}$ cells $(66,70,71)$. Factors, such as hypoxia inducible factor $1 \alpha($ HIF $1 \alpha)$ within the tumor microenvironment also promote differentiation of MDSCs into TAMs, creating a feedback loop to support immunosuppression $(66,72)$. Studies have shown that targeting MDSCs enhance anti-tumor immune responses in neuroblastoma $(73,74)$, suggesting that MDSCs play roles in cancer-related inflammation to enhance neuroblastoma tumor progression.

Hence, strategies to block accumulation of MDSCs, recruitment of MDSCs, or polarization of myeloid cells into immunosuppressive MDSCs are under investigation, and molecules targeting these strategies include all-trans retinoic acid (ATRA) and bevacizumab, and have been or are being studied in clinical trials for various cancers including neuroblastoma (27, 39). Interestingly, ATRA and 13-cis-retinoic acid (RA), another retinoic acid, also inhibit neuroblastoma cellular growth and promote differentiation of neuroblastoma cells (75). Phase I clinical trials demonstrated that 13-cis-RA had higher drug levels 
in patients with high-risk neuroblastoma after bone marrow transplantation (75-77). A subsequent Phase III clinical trial found that 13-cis-RA after bone marrow transplantation for high-risk neuroblastoma improved event-free survival with the most profound effect in patients with minimal residual disease, and 13-cis-RA remains an important component of consolidation therapy for high-risk neuroblastoma $(75,78)$. A Phase I clinical trial found combination treatment of ATRA and interferon- $\alpha 2 \mathrm{a}$ was well-tolerated in pediatric patients with refractory solid tumors; however, the Phase II clinical trial showed no response in pediatric patients with refractory or recurrent neuroblastoma and Wilms tumors $(79,80)$. For bevacizumab, one Phase II trial found that no improvement in response rates for bevacizumab in combination with irinotecan and temozolomide in pediatric patients with refractory or recurrent neuroblastoma compared to a historical cohort receiving irinotecan and temozolomide, while preliminary data from another recent Phase II study suggests bevacizumab and a temozolomide-based chemotherapy increased response rates compared to a temozolomide-based chemotherapy alone $(81,82)$.

Treg cells exhibit their suppressive activity via several mechanisms including inhibition of antigen-presenting cell maturation through the CTLA-4 pathway; secretion of inhibitory cytokines such as IL-10, TGF $\beta$, IL-35; and expression of granzyme and perforin which kills effector T-cells. Preclinical data generated in neuroblastoma mouse models indicates that depletion of Treg cells increases the efficacy of immunotherapy mediated by CD8 $+\mathrm{T}$ cells in vivo (83-85). The data regarding Treg cells remain less clear in patients with neuroblastoma. Some studies have shown an increased number of circulating Treg cells in patients with neuroblastoma compared to healthy individuals, but was not prognostic of outcomes $(86,87)$. In another report, lower frequency of Treg cells has been observed in the bone marrow and peripheral blood samples of patients with neuroblastoma compared to healthy controls (88). Interestingly, a higher proportion of Treg cells in the bone marrow and peripheral blood correlated with MYCN amplification (88).

Besides MDSCs and Tregs, TAMs are another cell population that is abundant in the neuroblastoma tumor microenvironment and represent a major driver of tumor immunosuppression in neuroblastoma. The next sections will focus on the role of TAMs in regulating tumor progression and immunosuppression, and the therapeutic potential of targeting TAMs in neuroblastoma.

\section{TAMs IN NEUROBLASTOMA}

TAMs are highly infiltrated in the solid tumors and display different phenotypes based on the environmental clues. In this section, we will discuss about the heterogeneity of macrophages, their functions and TAMs as prognostic factor in neuroblastoma.

\section{Macrophage Heterogeneity}

Macrophages are highly heterogeneous immune cells that are primarily phagocytic in nature and involved in host defense and tissue remodeling (89). In response to inflammation and various other environmental stimuli, a plethora of macrophage phenotypes can be induced, which can be generally classified into two main phenotypes based on their gene expression profiles (90). In the presence of lipopolysaccharide (LPS) or IFN $\gamma$, macrophages are polarized into classically activated M1 phenotype, producing immunostimulatory cytokines, phagocytosing target cells, and activating adaptive immune responses, whereas M2 polarized macrophages are activated by cytokines, such as IL-4 or IL-13, express scavenger receptors, and secrete vascular endothelial growth factor (VEGF), matrix metalloproteinase 9 (MMP9), IL-10, and TGF 3 . Many gene signatures have been identified that differentially associate with M1 and M2 macrophages, with M1 macrophages expressing Nos2, $I L-1 \beta$, IL-12 $\beta$, and $T N F-\alpha$, and M2 expressing Arg1, Chitinase 3-like-3 (Chi3l3), Resistin-like molecule alpha1 (Retnla/Fizz1), and CD206 (91-93). Unfortunately, the findings in in vitro studies do not always translate to in vivo (91-93). M1 and M2 macrophages also have diverse metabolism with M1 relying on glycolysis and expressing nitric oxide synthase and M2 relying on oxidative phosphorylation and expressing arginase (94, 95). Interestingly, data suggests that epigenetic factors also affect polarization of macrophages $(96,97)$. For example, IL-4 decreased histone $\mathrm{H} 3$ lysine-27 (H3K27) methylation at the promoters of M2-associated genes by increasing H3K27 demethylase Jumonji domain containing 3 (Jmjd3) expression in a Signal transducer and activator of transcription 6 (STAT6)dependent manner (96). These M2 macrophages play an important role in wound healing and tissue remodeling by promoting $\mathrm{T}$ helper 2 (Th2) response and dampening immune responses $(90,98)$.

In recent decades, further subtypes of M2 macrophages, including M2a, M2b, and M2c, have been identified. Stimulated by IL-4 and IL-13, M2a macrophages express cluster of differentiation 206 (CD206) and participate in wound healing by secretion of factors, including TGF- $\beta$ (99-101). $\mathrm{M} 2 \mathrm{~b}$ macrophages are induced by immune complexes with toll-like receptor (TLR) or IL-1R agonists, express TNF superfamily member 14 (TNFSF14), and dampen the immune and inflammatory processes in many diseases, including cancer, through release of cytokines, such as IL-10 (99-101). Induced by IL-10 and glucocorticoids, M2c macrophages express Mer receptor tyrosine kinase (MerTK) and also produce factors, such as TGF- $\beta$, and cytokines, such as IL10 , to promote tissue remodeling and dampen the immune response (99-101). Interestingly, these M2 subtypes also have distinctive metabolism. M2a and M2c macrophages, but not M2b macrophages, participate in the arginase pathway and utilize glycolysis, while M2b macrophages have increased production of nitric oxide and decreased production of urea $(99,102,103)$.

TAMs are macrophages within the tumor microenvironment, often express M2 macrophage markers, such as cluster of differentiation 163 (CD163) or CD206, and secrete VEGF, MMPs, and immunosuppressive cytokines, including IL-10 and TGF $\beta$, all of which dampen effective anti-tumor immune responses and promote tumor progression and metastasis (104). It is important to note that classification of these highly plastic cells as M1 or M2 is an oversimplification, and depending on the signals from tumor microenvironment, these macrophages can 
easily transition between different activation states fluctuating between M1 and M2 phenotype (98). Furthermore, a recent study demonstrated that tumor hypoxia can control slight variations of gene expression within M2-like TAMs to define a subpopulation of M2-like TAMs with a distinct phenotype to influence angiogenesis (105). Distinct subpopulations of TAMs, including perivascular TAMs and TAMs found at the tumor-stroma interface, have also been described in the tumor microenvironment, and these subsets of TAMs have differential expression of markers with some populations more M2-like and some less M2-like, and contribute to different aspects of tumor progression with perivascular TAMs contributing to metastasis and TAMs at the tumor-stroma interface promoting angiognesis (106-108). Further research is needed to better understand the molecular phenotypes and functional profiles of diverse macrophage subpopulations with the tumor microenvironment and uncover how the interplay between the subsets of TAMs works in concert with other immune cells within the tumor microenvironment and tumor cells to regulate tumorigenesis. Importantly, limitations remain regarding the applicability of preclinical studies of TAMs as these studies often treat TAMs as a single homogeneous population and in vivo models may not fully recapitulate the diversity of the human tumor microenvironment, including the heterogeneity of human tumors $(109,110)$. In addition, studies of TAMs in human tumors are limited by challenges from appropriate macrophage markers to standardization of quantification (111). Given this fluidity of polarization and limitations of current studies, we will discuss the polarization of TAMs throughout the review using the more simplified binary classification of M1 and M2 or M1-like and M2-like.

\section{TAMs Prognostic Factor in NB}

Studies have found that the presence of TAMs correlated with worse prognosis in various solid tumors including neuroblastoma $(25,112)$. In addition, evidence suggests that TAMs can facilitate progression of neuroblastoma $(25,67)$. One study used tissue microarrays to assess infiltration of TAMs by CD163 staining in tumor samples from patients with localized disease, stage 4 or metastatic disease, and stage $4 \mathrm{~S}$ disease (25). Stage $4 \mathrm{~S}$ is a unique classification for a subset of patients with metastatic neuroblastoma, defined as patients $<1$ year of age with a localized primary tumor and limited metastases to liver, skin, or bone marrow ( $<10 \%$ involvement), and portends an overall favorable prognosis with 5 -year OS of $~ 90 \%(25,113,114)$. Stage 4 metastatic tumors had significantly greater numbers of TAMs compared to localized tumors, while there was no significant difference in TAMs observed between Stage $4 \mathrm{~S}$ and localized tumors (25). Furthermore, the study reported that patients with an age $\geq 18$ months had higher tumor expression of TAMrelated genes including CD14, CD16, CD33, FCGR3, Il-10, and $I L 6 R$ compared to that of patients with age $\leq 18$ months; and age is known to be a prognostic factor and used to guide risk classification (25). Interestingly, a 14-gene signature was found to associate with progression-free survival and TAM-related genes (CD14, CD16, CD33, FCGR3, Il-10, and IL6R) contribute to $25 \%$ of the accuracy of the classification score (25).
A study of 102 non-MYCN-amplified neuroblastoma tumors demonstrated that these tumors express high level of inflammation-related genes expressed by M2 macrophages and identified a gene signature that consists of $I L-6$, IL-6 receptor (IL-6R), IL-10, and TGF $\beta$ and is associated with significantly worse prognosis (50). Interestingly, CD68-positive TAMs co-expressing IL- 6 was identified in the metastatic bone marrow samples of non-MYCN-amplified neuroblastoma (50). A recent study has shown that the presence of TAMs facilitated up-regulation of MYC protein expression through the signal transducer and activator of transcription 3 (STAT3) pathway in non-MYCN-amplified neuroblastoma tumor cells, suggesting this may at least partially explain the finding that TAMs are associated with poor survival in non-MYCN amplified tumors (67). In comparison, another study analyzing 23 neuroblastoma tumor samples found that stage IV neuroblastoma tumors had higher expression of M1 macrophage markers, IL1- $\beta$ and TNF$\alpha$, while stage I tumors had higher expression of M2 macrophage associated markers IL4, IL10, and TGF- $\beta$ with IL1- $\beta$ and TNF- $\alpha$ expression being associated with poor outcomes (115). These differences may be due to sample size, different subtype of neuroblastoma as the former study only included non-MYCN amplified tumors, or the locations of the biopsy samples as tumor microenvironments are often heterogeneous. Furthermore, stage IV tumors that express M1 macrophage markers may form a distinct subgroup of tumors as traditionally TAMs are thought to be M2 polarized and tumors that continue to develop despite a pro-immunostimulatory environment may portend poor outcomes. Taken together, these data suggest that TAMs play an integral role in neuroblastoma tumorigenesis and targeting TAMs may provide a novel treatment avenue in neuroblastoma; however, future studies are needed to clarify the phenotypes of TAMs within the neuroblastoma tumor microenvironment.

\section{Mechanisms of TAMs in Tumor Progression}

TAMs play a pivotal role in primary tumor progression, angiogenesis, metastasis, and immune suppression (116). TAMs interact with tumor cells and other immune cells of the tumor microenvironment to promote these events as shown in Figure 1 and described below.

\section{TAMs in Angiogenesis}

TAMs secrete various growth factors, including VEGF, Plateletderived growth factor (PDGF), TGF $\beta$, MMP2, and MMP9, which promote tumor growth by remodeling the extracellular matrix and stimulating neoangiogenesis $(117,118)$. Hypoxia is also a major contributor of tumor angiogenesis and studies have shown that TAMs are predominantly localized in hypoxic regions of tumors (119). A study by Pietras et al. has shown that HIF $2 \alpha$ and CD68-positive TAMs are found in close association with neural crest-like neuroblastoma cells and facilitate angiogenesis in neuroblastoma (120). To promote pro-angiogenic functions within tumors, TAMs up-regulate expression of HIF $1 \alpha / 2 \alpha$ which increases the transcription of various other pro-angiogenic factors like VEGF, TNF $\alpha$ and MMP. Hypoxia also stimulates the entry of TAMs in the tumor microenvironment by secreting several chemokines including 
CCL2, CCL20, and CSF1 (121, 122). Several studies have shown that CSF1 stimulates macrophages to secrete VEGF to promote angiogenesis $(121,123)$. Once macrophages are recruited in the tumors, hypoxia-dependent transcription factors HIF $1 / 2 \alpha$ reprograms macrophages into pro-tumoral phenotype that expresses IL-6, VEGF, and inducible nitric oxide synthase (iNOS) and arginase to promote tumor growth, angiogenesis, and immunosuppression $(124,125)$. While iNOS is typically induced by M1 macrophages, studies have found that M2-like TAMs express iNOS at lower levels than M1 macrophages and these low levels of NO produced by TAMs inhibits tumor cell apoptosis and serves a cytoprotective function (126-128). Recent studies have shown that PTEN/PI3K/AKT signaling axis and Syk-Rac2 signaling axis promotes the stabilization of HIF $1 / 2 \alpha$ in TAMs and polarization of macrophages into immunosuppressive phenotype in solid tumors (129-132). The inhibition of these signaling axes induces degradation of HIF $1 / 2 \alpha$ in a proteasomedependent manner and suppresses tumor growth and metastasis in solid tumors. The use of dual PI3K/BRD4 inhibitors SF1126 or SF2523 blocks tumor growth, angiogenesis, stabilization of HIF $1 / 2 \alpha$, and polarization of M2 macrophages in solid tumors including neuroblastoma (131, 133-135).

\section{TAMs in Metastasis}

TAMs also play an important role in tumor metastasis (104). VEGF and MMPs secreted by TAMs not only promote tumor angiogenesis, but also increase the permeability of blood vessels to facilitate extravasation. TAMs promote both the release of metastatic tumor cells from their primary site and establishment of tumor cells at secondary distant sites. In neuroblastoma, area of cancer-associated fibroblasts (CAFs) in the tumor microenvironment correlates with higher disease stage and higher risk stratification, and associated with increased TAMs (65). CAFs, TAMs, and tumor cells participate in crosstalk with neuroblastoma cells promoting activation of CAFs from bone marrow-derived mesenchymal stem cells and TAMs inducing increased invasion of CAFs, while CAFs can induce further neuroblastoma cell proliferation and inducing invasion of TAMs $(65,136)$. Moreover, CAFs release stromal cell-derived factor 1 (SDF1)/ C-X-C motif chemokine 12 (CXCL12) to recruit TAMs and endothelial progenitor cells to promote angiogenesis (137). CAFs also secrete TGF $\beta$ to facilitate epithelial to mesenchymal transition and in turn, TAMs promote mesenchymal to epithelial transition to enhance reactivity of CAFs $(138,139)$. Hashimoto et al. has shown that TAMs have increased expression of CXCL2 which enhances neuroblastoma tumor invasion through CXCL2/CXCR2 signaling (65). Our studies have shown that PTEN/PI3K signaling axis in macrophages promotes tumor metastasis and use of dual PI3K/BRD4 inhibitors SF1126 or SF2523 blocked tumor metastasis in neuroblastoma mouse model $(134,135)$.

\section{TAMs in Immunosuppression}

TAMs can promote immunosuppression in the tumor microenvironment by (1) suppressing the cytotoxic and metabolic activity of NK cells; (2) expanding Treg cells which indirectly suppress the function of effector T cells; (3) interacting with cytotoxic T cells in antigen-specific and antigen non-specific manners; and (4) stimulating MDSCs to secrete IL-10 which inhibits innate and adaptive immune responses.

The efficacy of anti-GD2 targeted immunotherapy in neuroblastoma relies on the antibody-dependent cellular cytotoxicity (ADCC) mediated by natural killer cells. Studies have shown that TAMs suppress the activity of NK cells in neuroblastoma (140). Song et al. found that high-risk neuroblastoma tumors contain CD68+ TAMs that secrete IL6 to suppress cytotoxic activity of NK cells (51). Xu et al. demonstrated co-culture of neuroblastoma tumor cells with macrophages leads to secretion of IL- 6 and TGF $\beta$, which inhibits cytotoxicity of IL-2 activated NK cells (140). Lenalidomide is an analog of thalidomide and has broad functions in diverse cancers, including direct anti-tumor activity, anti-angiogenic effects, and immunomodulatory effects (141). In terms of immunomodulating properties, lenalidomide induces T-cell activation and induces IL-2, IFN- $\gamma$, and TNF- $\alpha$ expression without requiring co-stimulation, while blocking IL- 6 and TGF $\beta$ secretion, which contribute to dysfunction of immune cells, including T-cells and dendritic cells (142). Lenalidomide has been extensively studied in multiple myeloma and hematologic malignancies (142); however, lenalidomide also enhances the activation of NK cells and improves survival in a xenograft model of neuroblastoma (140). In another study, Liu et al. showed that CCL20-producing TAMs generate a hypoxic trap for tumorinfiltrating NK T cells and IL-15 can protect antigen-activated NK $\mathrm{T}$ cells from hypoxia and immunosuppressive effects of TAMs (143).

In addition to regulating function of NK cells, TAMs also suppress the activation of CD8 $+\mathrm{T}$ cells by (1) generating anti-inflammatory cytokines which inhibits function of $\mathrm{T}$ cells, (2) depleting metabolites required for $\mathrm{T}$ cell proliferation, and (3) activating $\mathrm{T}$ cell checkpoint blockade through engagement of $\mathrm{T}$ cell receptors (39, 104, 144). TAM-derived enzymes arginase 1 and indoleamine dioxygenase 1/2 (IDO 1/2) catalyze metabolism of L-arginine and L-tryptophan respectively, and leads to suppression of effector $\mathrm{T}$ cell activation (110). A recent study showed that macrophage-derived IL-1 and TNF- $\alpha$ regulated arginine metabolism in neuroblastoma cells through a signaling pathway dependent on RAC-alpha serine/threonineprotein kinase (AKT) (115). Furthermore, in vitro studies suggest that neuroblastoma tumor cells can also promote M1 polarization of TAMs, leading to immune-metabolic cross-talk and a feedback loop that promotes neuroblastoma progression through tumor growth and immunosuppression (115); however, these findings have not yet been explored in vivo. Moreover, M2 macrophages preferentially promote oxidative phosphorylation and fatty acid oxidation over glycolysis, and increase availability of glucose for tumor cells (145). These changes in metabolism also supports Treg cells, which utilize oxidative phosphorylation, and inhibits CD4 + T cells, CD8 + T cells, and NK cells, which depend heavily on glycolysis (145-147). TAMs can also inhibit function of effector T cells by expressing ligands of inhibitory receptors PD-1 and CTLA-4. TAMs also up-regulate expression of Programmed death-ligand 1 (PD-L1), under the influence of HIF1 $\alpha$, leading to suppression of $\mathrm{T}$ cell activity in hypoxic tumor regions 
(148). PD-L1 has also been found to promote glycolysis in tumor cells that also compete for glucose with tumor-infiltrating lymphocytes, which also contributes to tumorigenesis (149). A recent study by Mao et al. found that myeloid cells isolated from neuroblastoma tumors express high levels of PDL1, and combining CSF1R inhibition with anti-PD1/PDL1 antibodies lead to better anti-tumor immune response and improved survival in mouse model of neuroblastoma (56). These preclinical data suggest that targeting TAMs either alone or in combination with checkpoint inhibitors may provide a novel treatment avenue in neuroblastoma and warrants further clinical investigation.

\section{TAM TARGETED IMMUNOTHERAPY IN NEUROBLASTOMA}

Given the abundant infiltration of macrophages in the tumor microenvironment and their diverse functions in promoting tumor growth, angiogenesis, metastasis, and immune escape, studies have found that TAMs may serve as an important target for immunotherapeutic strategies (150). TAM re-education has been proposed as an effective strategy to treat cancer. In particular, targeting this population has gained significant attention as this immune cell bears potential to reverse immunosuppression and synergize with checkpoint inhibitors or radiotherapy to activate cytotoxic $\mathrm{T}$ cells to kill tumors. To overcome the immunosuppressive functions of TAMs in neuroblastoma, current therapeutic strategies are aimed on three aspects as shown in Table $\mathbf{1}$ and Figure 2 and described in following sections:

\section{Inhibition of Macrophage Recruitment}

Inhibition of macrophage recruitment has shown great efficacy in blocking tumor growth and metastasis in various solid tumors including neuroblastoma $(56,122)$. Chemokines secreted by tumor cells, such as CCL2 and CSF1, recruit and polarize monocytes (161). One promising target, CSF-1 receptor (CSF1$\mathrm{R}$ ) is exclusively expressed on normal monocytes and plays a crucial role in regulating macrophage survival. Recent evidence suggests that CSF1-R infiltrating myeloid cells or monocytes correlates with poor clinical outcome in patients with neuroblastoma (56). One study found that CSF-1 blockade decreased neuroblastoma tumor growth in vivo and prolonged survival in the SK-NDZ neuroblastoma xenograft model, in which tumor cells do not express human CSF-1 (121). Antagonists and antibodies to CSF1R has been developed and tested in various preclinical mouse models. RG7155 (Emactuzumab) is a humanized monoclonal antibody that blocks CSF-1R activation and shows efficacy in mouse tumor models of colon cancer and fibrosarcoma, and a phase 1 clinical trial showed a partial response with emactuzumab in five of seven patients with diffuse-type tenosynovial giant cell tumors (162, 163). Another phase I trial studied emactuzumab with or without paclitaxel, in adult patients with advanced solid tumors and found that both monotherapy and combination with paclitaxel was largely safe with only one grade 5 toxicity, decreased CSF-1R+ and CD68+/CD163+ macrophages in the tumor microenvironment, and achieved a $7 \%$ response rate in patients receiving combination therapy with three patients with breast cancer and one patient with ovarian cancer achieving a partial response (164). PLX3397 (Pexidartinib) is a CSF1-R inhibitor and a phase II trial demonstrated efficacy of pexidartinib in patients with tenosynovial giant cell tumor with a 39\% response rate compared to $0 \%$ with placebo (NCT02371369) (165). Various clinical trials of this compound either alone or in combination with radiotherapy are under investigation for glioblastoma and other solid tumors (166). Another CSF-1R inhibitor, BLZ-945 blocked glioma progression and improved survival in various preclinical models (167).

Mao et al. reported that BLZ-945 modulates immunosuppressive myeloid cells and suppresses tumor progression in TH-MYCN mouse model of neuroblastoma (56). Interestingly, BLZ-945 in combination with anti-PD-1 antibody showed synergy in improving the survival of TH-MYCN mouse model of neuroblastoma with noted greater T-cell activation and infiltration into the tumor microenvironment (56). Depletion of TAMs in neuroblastoma mouse models potentiates the efficacy of chemotherapy even in the absence of T lymphocytes (122). BLZ-945 in combination with cyclophosphamide and topotecan inhibited neuroblastoma growth and improved survival in subcutaneous and intra-renal neuroblastoma tumors in immunodeficient NSG or NOD/SCID mice, suggesting that CSF-1R blockade with chemotherapy might be effective in patients with neuroblastoma and restricted anti-tumor $\mathrm{T}$ cell responses (122). This exciting data provides preclinical evidence that CSF1R inhibitors have therapeutic potential alone or in combination with chemotherapy or immunotherapy in neuroblastoma, and warrants further clinical investigation.

CCL2 is also an important chemokine secreted by tumor cells and endothelial cells to support infiltration of TAMs in tumors (168). Blockade of either CCL2 or its receptor CCR2 has shown anti-tumor activity in various preclinical models (169). In the Phase I clinical trial, administration of neutralizing antibodies against CCL2 (carlumab, CNTO888), was well tolerated and showed clinical reponse in patients with solid tumors; however, there was no response in the Phase II clinical trial for patients with castration-resistant prostate cancer $(170,171)$. Interestingly, sphingosine-1-phosphate (S1P) has been shown to be an important regulator of CCL2 expression in neuroblastoma, and preclinical studies suggest that inhibition of S1P2 leads to decreased CCL2 signaling and decreased macrophage infiltration in neuroblastoma tumors along with antitumor activity in vivo $(172,173)$.

\section{Targeting Macrophage Survival}

Strategies targeting the survival of macrophages are also under investigation for various solid tumors (56). Trabectidin (ET-743) is an anti-tumor agent recently shown to deplete circulating monocytes and TAMs in cancer patients (154, 174). Trabectidin activates caspase- 8 dependent apoptosis in mononuclear phagocytes and shows anti-tumor activity mainly due to its cytotoxic effects on TAMs. Trabectedin-induced TAM reduction was associated with decreased angiogenesis in murine tumors and human sarcomas (154). The combination 
TABLE 1 | Therapeutic approaches to target TAMs in neuroblastoma.

\begin{tabular}{|c|c|c|c|c|c|c|}
\hline $\begin{array}{l}\text { Mechanism of } \\
\text { action }\end{array}$ & Target & $\begin{array}{l}\text { Treatment } \\
\text { strategy }\end{array}$ & $\begin{array}{l}\text { Macrophage } \\
\text { markers }\end{array}$ & In vivo model & Outcome & References \\
\hline \multirow[t]{3}{*}{$\begin{array}{l}\text { Inhibition of } \\
\text { macrophage } \\
\text { recruitment }\end{array}$} & CSF1 & $\begin{array}{l}\text { siRNA knockdown } \\
\text { of CSF-1 }\end{array}$ & $\mathrm{F} 4 / 80^{+}, \mathrm{Tie}^{-} 2^{+}$ & $\begin{array}{l}\text { SK-N-DZ athymic nu/nu } \\
\text { (nude) xenograft mouse } \\
\text { model }\end{array}$ & $\begin{array}{l}\text { Decreased TAMs; decreased } \\
\text { tumor growth; increased survival }\end{array}$ & $(121)$ \\
\hline & CSF1R & $\begin{array}{l}\text { BLZ-945 + } \\
\text { anti-CSF-1 mAbs } \\
\text { (MCS110 and } \\
5 \mathrm{~A} 1)+ \\
\text { cyclophosphamide } \\
+ \text { topotecan }\end{array}$ & $\begin{array}{l}\text { Ly6G }^{-} \\
\text {CD11b+F } 4 / 80^{+}\end{array}$ & $\begin{array}{l}\text { CHLA-255-Fluc NOD/SCID } \\
\text { xenograft mouse model }\end{array}$ & $\begin{array}{l}\text { Decreased TAMs; decreased } \\
\text { tumor growth; increased survival }\end{array}$ & $(122)$ \\
\hline & & $\begin{array}{l}\text { BLZ-945 + } \\
\text { anti-PD1 }\end{array}$ & $\mathrm{CD} 11 \mathrm{~b}^{+} \mathrm{F} 4 / 80^{+}$ & $\begin{array}{l}\text { TH-MYCN transgenic } \\
\text { mouse model }\end{array}$ & $\begin{array}{l}\text { Decreased TAMs, decreased } \\
\text { tumor growth }\end{array}$ & $(56)$ \\
\hline \multirow[t]{3}{*}{$\begin{array}{l}\text { Intervention with } \\
\text { TAM survival }\end{array}$} & Osteoclasts & $\begin{array}{l}\text { Ibandronate/ } \\
\text { bisphosphonate }\end{array}$ & TRAP + & $\begin{array}{l}\text { SK-N-BE athymic nude } \\
\text { xenograft mouse model }\end{array}$ & $\begin{array}{l}\text { Decreased number of osteolytic } \\
\text { lesions }\end{array}$ & $(151)$ \\
\hline & Legumain & LEG3 & CD68+ & $\begin{array}{l}\text { C1300 A/J xenograft mouse } \\
\text { model }\end{array}$ & $\begin{array}{l}\text { Decreased tumor growth; } \\
\text { Increased survival }\end{array}$ & $(152)$ \\
\hline & $\begin{array}{l}\text { TRAIL } \\
\text { receptors }\end{array}$ & $\begin{array}{l}\text { Trabectidin + } \\
\text { cisplatin }\end{array}$ & $\mathrm{F} 4 / 80+$ & $\begin{array}{l}\text { SK-N-DX athymic nude } \\
\text { xenograft mouse model }\end{array}$ & Decreased tumor growth & $(153,154)$ \\
\hline \multirow[t]{7}{*}{$\begin{array}{l}\text { Repolarization of } \\
\text { macrophages }\end{array}$} & Rac2 & $\begin{array}{l}\text { Genetic deletion of } \\
\text { Rac2 }\end{array}$ & $\mathrm{F} 4 / 80^{+}$ & $\begin{array}{l}\text { 9464D-GD2 syngeneic } \\
\text { mouse model }\end{array}$ & $\begin{array}{l}\text { Decreased tumor growth and } \\
\text { polarization of M2 macrophages }\end{array}$ & $(130)$ \\
\hline & BRD4 & JQ1 & $\mathrm{F} 4 / 80+$ & $\begin{array}{l}\text { BE(2)-C-LucNeo NOD/SCID } \\
\text { xenograft mouse model; } \\
\text { SFNB-06 athymic nude } \\
\text { xenograft mouse model; } \\
\text { TH-MYCN transgenic } \\
\text { mouse model }\end{array}$ & $\begin{array}{l}\text { Decreased tumor growth; } \\
\text { increased survival; Blocked } \\
\text { polarization of M2 macrophages } \\
\text { in vitro }\end{array}$ & $\begin{array}{l}(134,135,155 \\
156)\end{array}$ \\
\hline & HDAC & Vorinostat & $\begin{array}{l}\text { CD11C } \mathrm{C}^{\text {dim }} \mathrm{F} 4 / 80^{\text {high }} \\
\mathrm{MHCl}{ }^{\text {int }}\end{array}$ & $\begin{array}{l}\text { TH-MYCN transgenic } \\
\text { mouse model }\end{array}$ & $\begin{array}{l}\text { Increased expression of CD163, } \\
\text { IL4Ra, FCRg1, FCRg3, FCRg4; } \\
\text { Decreased expression of FIZZ1, } \\
\text { YM1, Arginase; Decreased } \\
\text { tumor growth }\end{array}$ & $(157)$ \\
\hline & PI3K/BRD4 & SF2523 & $\begin{array}{l}\mathrm{CD} 11 \mathrm{~b}^{+} \mathrm{F} 4 / 80^{+} \\
\mathrm{CD}^{+} 06^{+}\end{array}$ & $\begin{array}{l}\text { SKNBE2 athymic nu/nu } \\
\text { (nude) xenograft mouse } \\
\text { model }\end{array}$ & $\begin{array}{l}\text { Suppressed polarization of M2 } \\
\text { macrophages in vitro; Decreased } \\
\text { tumor growth }\end{array}$ & $(134,135)$ \\
\hline & JAK1/2 & Ruxolitinib & $\mathrm{CD} 11 \mathrm{~b}^{+} \mathrm{F} 4 / 80^{+}$ & $\begin{array}{l}\text { NBT2 NOD/SCID xenograft } \\
\text { mouse model }\end{array}$ & $\begin{array}{l}\text { No evaluation of TAM-associated } \\
\text { markers in vivo; Decreased } \\
\text { tumor growth }\end{array}$ & $(67,89)$ \\
\hline & CD40 & Anti-CD40 +CpG & $\mathrm{CD} 11 \mathrm{~b}^{+} \mathrm{F} 4 / 80^{+}$ & $\begin{array}{l}\text { NSX2 NOD/SCID xenograft } \\
\text { mouse model }\end{array}$ & $\begin{array}{l}\text { No evaluation of TAM-associated } \\
\text { markers in vivo; Decreased } \\
\text { tumor growth; Increased survival }\end{array}$ & $(158,159)$ \\
\hline & & $\begin{array}{l}\text { Anti-CD40+ CpG } \\
+ \text { anti-CTLA-4 }\end{array}$ & Ly6G-CD11b+ & $\begin{array}{l}\text { 9464D-GD2 syngeneic } \\
\text { mouse model }\end{array}$ & $\begin{array}{l}\text { No evaluation of TAM-associated } \\
\text { markers in vivo; decreased } \\
\text { tumor growth }\end{array}$ & $(159,160)$ \\
\hline
\end{tabular}

of cisplatin and trabectidin has shown anti-tumor activity in neuroblastoma xenografts (153). Although this study didn't evaluate if administration of trabectidin can deplete monocytes, its findings suggest that trabectedin has activity in neuroblastoma and future studies should explore whether this drug can deplete macrophages to enhance anti-tumor immune responses in neuroblastoma.

Ongoing research has also examined the role of using activated NK cells to deplete the monocyte or macrophage population. CD1d is a MHC class I-related protein that is used by antigenpresenting cells to present lipid and glycolipid antigens that are subsequently recognized by NK $\mathrm{T}$ cells and leads to NK T cell activation $(175,176)$. Traditionally, NK T-cell therapy has been used to target tumor cells, and while neuroblastoma tumor cells do not express CD1d, studies have found that inducing exogenous CD1d expression in neuroblastoma tumor cells with pulsed $\alpha$-Galactosylceramide activated NK T cells and produced NK T cell anti-tumor activity (177). Interestingly, TAMs in the neuroblastoma tumor microenvironment are CD1d-positive, and transferring activated NK $\mathrm{T}$ cells led to increased cell death of TAMs in a CD1d-restricted manner and decreased tumor proliferation in vivo (51). Interestingly, NK T cell anti-tumor activity was not observed for in vivo models using tumors grown in the absence of monocytes, suggesting that the decreased tumor growth is specific to NK T cell killing of TAMs (51). Furthermore, CD105 is a transmembrane coreceptor for TGF $\beta$ 


\section{Targeting macrophage survival}

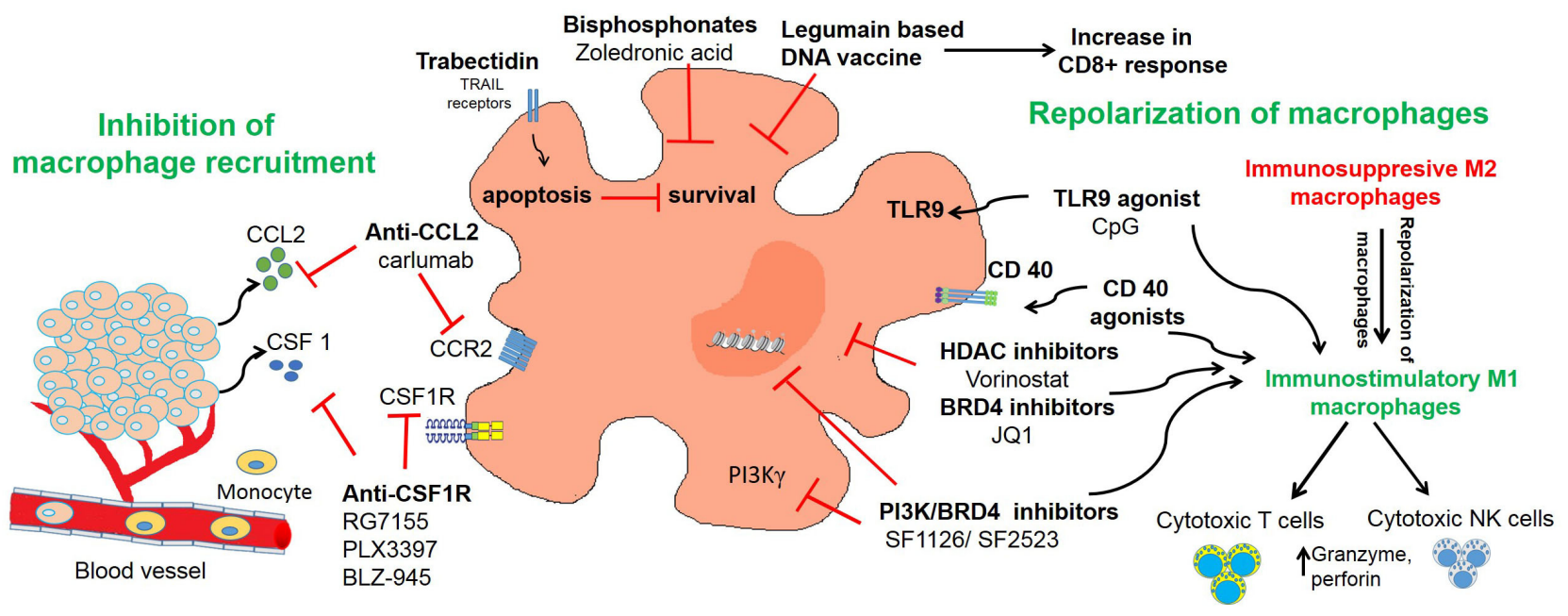

FIGURE 2 | Targeting of macrophages as an effective strategy to improve anti-tumor immune responses in neuroblastoma. The figure illustrates three different strategies used in neuroblastoma to inhibit recruitment of macrophages or to deplete TAMs or to repolarize M2 macrophages into M1 macrophages.

and bone morphogenetic protein-9 (BMP-9) and many immune cell populations within the tumor microenvironment, including MSCs, CAFs, proliferating endothelial cells, and TAMs express CD105 (178-182). Use of CD105 antibodies to deplete CD105positive immune cells, including macrophages, from the tumor microenvironment in addition to dinutuximab and activated NK cells decreased tumor growth and improved survival in murine models of neuroblastoma as well as a patient xenograft model compared to other combinations of therapy (182).

Some other treatment strategies in neuroblastoma that decrease macrophage survival also have anti-tumor activity. Bisphosphonates have long been used for the treatment of osteoporosis and osteolytic lesions by bone metastasis in neuroblastoma (151, 183-185). Recent studies have shown that bisphosphonates have anti-tumor activity and are cytotoxic against myeloid cells, tissue macrophages, and TAMs (186). Vorotnjak et al. has evaluated the anti-tumor effect of bisphosphonates on neuroblastoma cells and found that nitrogen-containing bisphosphonates are more cytotoxic than non-nitrogen containing bisphosphonates (187). Sohara et al. found that osteoclasts (bone macrophages) contribute to neuroblastoma bone metastases and demonstrated that treatment of mice engrafted with neuroblastoma tumors with bisphosphonates can delay the progression of osteolytic lesions (151). Zoledronic acid is a nitrogen-containing bisphosphonate that has been used for the treatment of bone metastasis in solid tumors (188). Peng et al. has shown that zoledronic acid inhibits the activity of osteoclasts within neuroblastoma bone lesions, but also blocks the proliferation and survival of tumor cells, and in combination with cytotoxic chemotherapy prolongs survival of mouse model of neuroblastoma with bone invasion (183). On the basis of these preclinical studies, a phase I clinical trial evaluated the efficacy of zoledronic acid with low-dose cyclophosphamide in patients with refractory neuroblastoma. The results of this phase I trial suggest that this combination was well-tolerated and decreased osteoclast activity and serum IL-6 levels in patients with relapsed or refractory neuroblastoma (185). A subsequent Phase I study from the New Approaches to Neuroblastoma Therapy Consortium (NCT00885326) explored the safety of bevacizumab, cyclophosphamide, and zoledronic acid in patients with recurrent or refractory high-risk neuroblastoma with a secondary aim of tumor response, and while it has completed accrual, preliminary data is not yet available. Future research is needed to assess the contribution of osteoclasts and TAMs in metastatic neuroblastoma and whether the efficacy of bisphosphonates in neuroblastoma is dependent on its effect on osteoclasts, anti-tumor activity, or both.

Furthermore, strategies aimed at targeting cell surface proteins of M2 macrophages is also under investigation in preclinical models. Legumain is a promising target as it is expressed on

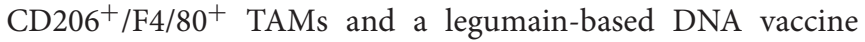
induced a robust $\mathrm{CD} 8+\mathrm{T}$ cell response against TAMs in murine models of metastatic breast cancer, colon cancer and non-small cell lung cancer (189). In the syngeneic C1300 neuroblastoma tumor model, legumain-activated doxorubicin prodrug LEG3 has anti-tumor activity (152). While $\mathrm{Wu}$ et al. did not explore the effect of legumain on the tumor microenvironment and TAMs, the syngeneic neuroblastoma tumor model has an intact immune system, it is possible effects on the tumor microenvironment may have contributed to the decrease in tumor growth and improved survival. Thus, future studies are need to understand the role of legumain on regulating immune cell populations, particularly, TAMs, in neuroblastoma. Given the crosstalk between tumor cells and immune cell populations, novel treatments may need to target multiple pathways, and the strategy of eliminating TAMs 
either alone or in conjunction with agents showing anti-tumor activity still needs further investigation in neuroblastoma.

\section{Repolarization of Macrophages}

Macrophage repolarization is another cancer immunotherapy strategy under investigation as fine-tuning their functional plasticity can transition pro-tumor macrophages into antitumor M1 macrophages (190). Agents that can polarize macrophages into anti-tumorigenic phenotype can be beneficial in cancer therapy. M2-like TAMs inhibit the activation of $\mathrm{CD} 8+\mathrm{T}$ cells and NK cells and repolarization of macrophages into M1 phenotype activates CD8+ T cells and NK cells (Figure 2). One strategy to repolarize macrophages in vivo is the inhibition of Syk-Rac2 signaling axis. Our group has identified a novel signaling pathway by which $\alpha_{4} \beta_{1}$ integrin and CSF receptor activates Syk-PI3K $\gamma$-Rac2 axes to polarize macrophages into immunosuppressive phenotype (130-132). Rac2 is a hematopoietic GTPase and our studies have shown that macrophage deletion of Rac2 blocks tumor growth in syngeneic NB9464 model of neuroblastoma (130). Moreover, genetic deletion or pharmacological inhibition of macrophage Syk kinase induces proinflammatory transcriptional programming in macrophages which resulted in activated $\mathrm{T}$ cell responses in lung adenocarcinoma and B16 melanoma model (132). These studies also identified that Syk kinase regulates stabilization of HIF $1 / 2 \alpha$ to promote immunosuppression in TME while inhibition of Syk kinase promotes activation of $\mathrm{NF}-\kappa \mathrm{B}$, leading to immunostimulation and tumor regression. $\mathrm{PI} 3 \mathrm{~K} \gamma$ is another molecular target that is highly expressed in macrophages and promotes anti-inflammatory polarization of macrophages in solid tumors $(131,135)$. Our recent study demonstrated that combinatorial inhibition of SykPI3K $\gamma$ axis by a dual Syk-PI3K $\gamma$ inhibitor SRX3207 has shown great efficacy in solid tumors (132). Other strategies to repolarize macrophages include targeting histone deacetylase (HDAC) proteins or epigenetic reader proteins, including bromodomain-containing proteins (BRD). We have recently shown that BRD4 promotes polarization of macrophages into anti-inflammatory phenotype and treatment with bromodomain inhibitor JQ1 or dual PI3K/BRD4 inhibitor SF1126 or SF2523 blocks immunosuppression and promotes adaptive immune responses in solid tumors including neuroblastoma (131, 134, $135,155,156)$. Vorinostat, a histone deacetylase inhibitor, also promotes M1 repolarization of TAMs, along with increased GD2 expression on neuroblastoma cells with combination of vorinostat and anti-GD2 immunotherapy showing synergy in vivo (157).

Another target to repolarize macrophages is Janus kinase 2 (JAK2)/STAT3 pathways. STAT3 is activated in myeloid cells and promote tumor immunosuppression (191). The presence of TAMs upregulated the activation of STAT3 pathway in neuroblastoma tumor cells and administration of JAK/STAT inhibitor AZD1480 reduced TAM-mediated growth of neuroblastoma (67).

In recent years, emerging evidence shows that CD40 plays a critical role in regulating antitumor effector macrophages with M1 polarization, leading to production of IFN- $\gamma$, IL-12, and nitric oxide (NO) to help mediate tumor killing (192, 193). Agonistic anti-CD40 antibodies induce tumoricidal effects against neuroblastoma cells in vivo $(192,194,195)$. Buhtoiarov et al. has shown that anti-CD40 antibody in combination with CpG-containing oligodeoxynucleotides ( $\mathrm{CpG})$, a toll-like receptor 9 agonist led to activation of tumoristatic macrophages and promoted anti-tumor immunity in NXS2 mouse model of neuroblastoma model (158). Voeller et al. studied two syngeneic murine models of neuroblastoma, NXS2, and NMYC driven 9464D-GD2, which have moderate and low tumor mutational burden (TMB), respectively. Radiation and treatment with immunocytokine hu14.18-IL2, a fusion protein linking hu14.18 anti-GD2 $\mathrm{mAb}$ and IL2, produced significant anti-tumor response in NXS2 mice, but not in N-MYC driven 9464D-GD2 mice, compared to monotherapy. While the addition of CTLA-4 inhibition alone was not effective in N-MYC driven 9464D-GD2 mice, treatment with $\mathrm{CpG}$, and anti-CD40 in addition to antiCTLA-4, radiation, and the immunocytokine produced complete tumor regression in four of five mice, and increased macrophages and decreased Treg cells within the tumor microenvironment. On rechallenge experiments, tumors grew significantly slower in previously treated mice compared to treatment-naïve mice, suggesting a memory response (160).

Other macrophage repolarization strategies have also been explored for neuroblastoma. Relation et al. demonstrated that MSC-associated delivery of IFN- $\gamma$ directly to the tumor microenvironment causes M1 polarization of TAMs, leading to significantly decreased tumor growth and increased survival in a model of metastatic neuroblastoma (196). In addition, prostaglandin $\mathrm{E}_{2} \quad\left(\mathrm{PGE}_{2}\right)$ promotes neuroblastoma tumor growth through multiple pathways, including facilitating M2 macrophage polarization, and inhibition of PGE2 leads to repolarization of macrophages to a M1 state and reduced tumor growth in TH-MYCN transgenic mice (197). Finally, delivery of an oncolytic virus containing an antagonist of C$\mathrm{X}$-C motif chemokine receptor 4 (CXCR4) alters the tumor microenvironment with decreased Treg cells and increased proportion of immunostimulatory macrophages (198).

\section{LIMITATIONS OF IN VIVO PRECLINICAL MODELS OF NEUROBLASTOMA TO STUDY TAMs}

Preclinical models play an important role in drug discovery for many cancers, including neuroblastoma, but each model is not without its limitations and likely contribute to the high failure rate of promising preclinical targets in clinical trials (199203). Xenograft, transgenic, and syngeneic neuroblastoma mouse models are frequently used to characterize the role of TAMs in neuroblastoma and investigate novel therapeutic avenues. Established neuroblastoma cell lines are often used as they have been heavily characterized, but due to selection in an in vitro environment, these cell lines may acquire additional genetic alterations that are distinct from neuroblastoma tumors and influence the results generated (203). Patient-derived xenografts can be excellent models because they are derived from a 
patient's tumor sample and therefore recapitulate molecular and phenotypic features that resemble neuroblastoma tumors (203). Moveover, xenograft models are generated by using immunodeficient mice, such as athymic nude mice, which carry loss of forkheadbox $n 1$ (Foxn1), and severely compromised immunodeficient (SCID) mice $(200,202,203)$. Atymic nude mice lack mature $\mathrm{T}$ cells, but continue to have myeloid cells and have innate immunity pathways, which often makes these mice, an excellent in vivo model to study TAMs and MDSCs (204). Nonetheless, crosstalk and interplay between the diverse immune populations, including T cells and TAMs, are important in regulating neuroblastoma tumor growth. Thus, these models have a compromised immune system that does not completely recapitulate the complex tumor microenvironment in patients with neuroblastoma.

There are several transgenic models of neuroblastoma, including the widely used TH-MYCN neuroblastoma model (205-208). The TH-MYCN neuroblastoma model overexpressing MYCN in neuroectodermal cells through the use of a tyrosine hydroxylase promoter; however, the incidence of spontaneous neuroblastoma varies between 5 and $20 \%$ in $\mathrm{C} 57 \mathrm{Bl} / \mathrm{N}$ background to $40 \%$ in the $129 \mathrm{X} 1 / \mathrm{SvJ}$ background, suggesting other genetic factors may contribute to the development of neuroblastoma $(205,207)$. Recently, a Cre-conditional mouse model of neuroblastoma (LSLMYCN;Dbh-iCre), and induces conditional expression of MYCN in dopamine $\beta$-hydroxylase-expressing cells through Cre recombination and carries $\sim 75 \%$ incidence of spontaneous tumor development regardless of strain background (208). Mutation in anaplastic lymphoma kinase (ALK) have been recently found it a subset of patients with neuroblastoma and a transgenic mouse model expressing $\mathrm{ALK}^{\mathrm{F} 1174 \mathrm{~L}}$ in neural stem cells was generated using either Cre recombination in either dopamine $\beta$-hydroxylase- or tyrosine hydroxylaseexpressing cells (206). While these mice have an intact immune system, which is excellent for studying the tumor microenvironment, these models depend on MYCN overexpression or $\mathrm{ALK}^{\mathrm{F} 1174 \mathrm{~L}}$ targeted expression, which only captures a subset of neuroblastoma cases, and may not be representative for non-MYCN amplified and non-ALK mutated disease. Little is currently known about the differences in tumor microenvironment for tumors with different oncogenic driver mutations and it is possible the immune response is different between each of these models. Furthermore, the TH-MYCN and $\mathrm{ALK}^{\mathrm{F} 1174 \mathrm{~L}}$ transgenic mouse models have a low incidence of bone metastases $(205,206)$, suggesting that tumors from patients with high-risk neuroblastoma, in whom bone metastases are common, may be different from those that develop in these transgenic models.

Syngeneic mouse models are generated by using neuroblastoma cell lines that were originally derived from genetically engineered models to generated allograft mouse models of neuroblastoma (209). Unlike transgenic mouse models, the mutations are only present in the tumor cells that are used to generate the allograft model, thereby limiting any potential off target effects, these cell lines can be modified to have additional mutations or improve imaging or tracking of tumors, and these mice have a fully functioning immune system, which can better mimic the tumor and tumor microenvironment (209). However, similar to xenograft models, the cell lines may have genetic alterations as they are grown in vitro, and similar to transgenic models, these cell lines will only carry the specific mutations introduced in the genetically engineered mouse models. Furthermore, unlike patient xenografts, some of the tumor heterogeneity may not be fully recapitulated $(199,209)$.

Many preclinical in vivo models can be used to study TAMs and the tumor microenvironment and many studies have identified novel treatment strategies that warrant further evaluation in clinical studies for patients with neuroblastoma (Table 1). Although each type of model has various advantages and disadvantages, these studies continue to provide a better characterization of the tumor microenvironment within neuroblastoma and further understanding of novel pathways that are integral to neuroblastoma tumor progression. Due to the limitations of these models, it is possible that the treatment strategies identified within these preclinical studies may benefit a subset of patients with neuroblastoma and patient selection may be important for future clinical investigations.

\section{CONCLUSION}

While the tumor microenvironment in neuroblastoma is complex and are comprised of many players, including CAFs, TAMs, T-cells and other immune cells, increasing evidence suggest that TAMs are central regulators of tumor progression and contribute to tumor immunosuppression, and serve as a novel target for future treatment strategies in neuroblastoma. Novel therapeutic agents blocking TAM recruitment, depleting macrophages, or repolarizing macrophages to M1 states have been under investigation in preclinical models of neuroblastoma with promising outcomes. It remains important to recognize that these novel strategies have other effects on the tumor microenvironment beyond TAMs and may also have anti-tumor activity. Given the complex cross-talk within the tumor microenvironment between tumor cells and immune cell populations, drug targets or immunotherapies that target multiple pathogenic pathways may be important. Future studies will further delineate signaling mechanisms utilized by these innate immune cells to promote immunosuppression and identify novel treatment strategies to re-activate the tumor immune response and overcome checkpoint blockade in neuroblastoma.

\section{AUTHOR CONTRIBUTIONS}

KL wrote and reviewed the manuscript. SJ wrote, reviewed, and proofread the manuscript. Both authors contributed to the article and approved the submitted version.

\section{FUNDING}

This work was supported in part by NIH grant K22 CA229594 to SJ. 


\section{REFERENCES}

1. He WG, Yan Y, Tang W, Cai R, Ren G. Clinical and biological features of neuroblastic tumors: a comparison of neuroblastoma and ganglioneuroblastoma. Oncotarget. (2017) 8:37730-9. doi: 10.18632/oncotarget.17146

2. Ruiz-Perez MV, Henley AB, Arsenian-Henriksson M. The MYCN protein in health and disease. Genes. (2017) 8:113. doi: 10.3390/genes8040113

3. Cohn SL, Pearson AD, London WB, Monclair T, Ambros PF, Brodeur GM, et al. The International Neuroblastoma Risk Group (INRG) classification system: an INRG Task Force report. J Clin Oncol. (2009) 27:289-97. doi: 10.1200/JCO.2008.16.6785

4. Monclair T, Brodeur GM, Ambros PF, Brisse HJ, Cecchetto G, Holmes $\mathrm{K}$, et al. The International Neuroblastoma Risk Group (INRG) staging system: an INRG Task Force report. J Clin Oncol. (2009) 27:298-303. doi: 10.1200/JCO.2008.16.6876

5. Tolbert VP, Matthay KK. Neuroblastoma: clinical and biological approach to risk stratification and treatment. Cell Tissue Res. (2018) 372:195-209. doi: 10.1007/s00441-018-2821-2

6. Sokol E, Desai AV. The evolution of risk classification for neuroblastoma. Children. (2019) 6:27. doi: 10.3390/children6020027

7. Seeger RC, Brodeur GM, Sather H, Dalton A, Siegel SE, Wong KY, et al. Association of multiple copies of the N-myc oncogene with rapid progression of neuroblastomas. N Engl J Med. (1985) 313:1111-6. doi: 10.1056/NEJM198510313131802

8. Kreissman SG, Seeger RC, Matthay KK, London WB, Sposto R, Grupp SA, et al. Purged versus non-purged peripheral blood stem-cell transplantation for high-risk neuroblastoma (COG A3973): a randomised phase 3 trial. Lancet Oncol. (2013) 14:999-1008. doi: 10.1016/S1470-2045(13)70309-7

9. Wang LL, Teshiba R, Ikegaki N, Tang XX, Naranjo A, London WB, et al. Augmented expression of MYC and/or MYCN protein defines highly aggressive MYC-driven neuroblastoma: a Children's Oncology Group study. Br J Cancer. (2015) 113:57-63. doi: 10.1038/bjc.2015.188

10. Park JR, Kreissman SG, London WB, Naranjo A, Cohn SL, Hogarty MD, et al. Effect of tandem autologous stem cell transplant vs single transplant on event-free survival in patients with high-risk neuroblastoma: a randomized clinical trial. JAMA. (2019) 322:746-55. doi: 10.1001/jama.2019.11642

11. Strother DR, London WB, Schmidt ML, Brodeur GM, Shimada H, Thorner P, et al. Outcome after surgery alone or with restricted use of chemotherapy for patients with low-risk neuroblastoma: results of Children's Oncology Group study P9641. J Clin Oncol. (2012) 30:1842-8. doi: 10.1200/JCO.2011.37.9990

12. Park JR, Bagatell R, London WB, Maris JM, Cohn SL, Mattay KK, et al. Children's Oncology Group's 2013 blueprint for research: neuroblastoma. Pediatr Blood Cancer. (2013) 60:985-93. doi: 10.1002/pbc.24433

13. Baker DL, Schmidt ML, Cohn SL, Maris JM, London WB, Buxton A, et al. Outcome after reduced chemotherapy for intermediate-risk neuroblastoma. N Engl J Med. (2010) 363:1313-23. doi: 10.1056/NEJMoa1001527

14. Maris JM. Recent advances in neuroblastoma. N Engl J Med. (2010) 362:2202-11. doi: 10.1056/NEJMra0804577

15. Matthay KK, Maris JM, Schleiermacher G, Nakagawara A, Mackall CL, Diller L, et al. Neuroblastoma. Nat Rev Dis Primers. (2016) 2:16078. doi: $10.1038 / \mathrm{nrdp} .2016 .78$

16. Coughlan D, Gianferante M, Lynch CF, Stevens JL, Harlan LC. Treatment and survival of childhood neuroblastoma: evidence from a populationbased study in the United States. Pediatr Hematol Oncol. (2017) 34:320-30. doi: 10.1080/08880018.2017.1373315

17. Liu KX, Naranjo A, Zhang FF, Dubois SG, Braunstein SE, Voss SD, et al. Prospective evaluation of radiation dose escalation in patients with high-risk neuroblastoma and gross residual disease after surgery: a report from the Children's Oncology Group ANBL0532 Study. J Clin Oncol. (2020) 1903316. doi: 10.1200/JCO.19.03316. [Epub ahead of print].

18. $\mathrm{Yu}, \mathrm{AL}$, Uttenreuther-Fischer MM, Huang CS, Tsui CC, Gillies SD, Reisfeld RA, et al. Phase I trial of a human-mouse chimeric antidisialoganglioside monoclonal antibody ch14.18 in patients with refractory neuroblastoma and osteosarcoma. J Clin Oncol. (1998) 16:2169-80. doi: 10.1200/JCO.1998.16.6.2169
19. Kushner $\mathrm{BH}$, Kramer $\mathrm{K}$, Cheung NK. Phase II trial of the antiG(D2) monoclonal antibody 3F8 and granulocyte-macrophage colonystimulating factor for neuroblastoma. J Clin Oncol. (2001) 19:4189-94. doi: 10.1200/JCO.2001.19.22.4189

20. Yu AL, Gilman AL, Ozkaynak MF, London WB, Kreissman SG, Chen HX, et al. Anti-GD2 antibody with GM-CSF, interleukin-2, and isotretinoin for neuroblastoma. N Engl J Med. (2010) 363:1324-34. doi: 10.1056/NEJMoa0911123

21. Ladenstein R, Potschger U, Valteau-Couanet D, Luksch R, Castel V, Yaniv I, et al. Interleukin 2 with anti-GD2 antibody ch14.18/CHO (dinutuximab beta) in patients with high-risk neuroblastoma (HR-NBL1/SIOPEN): a multicentre, randomised, phase 3 trial. Lancet Oncol. (2018) 19:1617-29. doi: 10.1016/S1470-2045(18)30578-3

22. Park JR, Digiusto DL, Slovak M, Wright C, Naranjo A, Wagner J, et al. Adoptive transfer of chimeric antigen receptor re-directed cytolytic $\mathrm{T}$ lymphocyte clones in patients with neuroblastoma. Mol Ther. (2007) 15:82533. doi: 10.1038/sj.mt.6300104

23. Louis CU, Savoldo B, Dotti G, Pule M, Yvon E, Myers GD, et al. Antitumor activity and long-term fate of chimeric antigen receptorpositive T cells in patients with neuroblastoma. Blood. (2011) 118:6050-6. doi: 10.1182/blood-2011-05-354449

24. Straathof K, Flutter B, Wallace R, Thomas S, Cheung G, Collura A, et al. Abstract CT145: A Cancer Research UK phase I trial of anti-GD2 chimeric antigen receptor (CAR) transduced T-cells (1RG-CART) in patients with relapsed or refractory neuroblastoma. Cancer Res. (2018) 78:CT145. doi: 10.1158/1538-7445.AM2018-CT145

25. Asgharzadeh S, Salo JA, Ji L, Oberthuer A, Fischer M, Berthold $\mathrm{F}$, et al. Clinical significance of tumor-associated inflammatory cells in metastatic neuroblastoma. J Clin Oncol. (2012) 30:3525-32. doi: 10.1200/JCO.2011.40.9169

26. Orentas RJ, Yang JJ, Wen X, Wei JS, Mackall CL, Khan J. Identification of cell surface proteins as potential immunotherapy targets in 12 pediatric cancers. Front Oncol. (2012) 2:194. doi: 10.3389/fonc.2012.00194

27. Long AH, Highfill SL, Cui Y, Smith JP, Walker AJ, Ramakrishna S, et al. Reduction of MDSCs with all-trans retinoic acid improves CAR therapy efficacy for sarcomas. Cancer Immunol Res. (2016) 4:869-80. doi: 10.1158/2326-6066.CIR-15-0230

28. Bosse KR, Raman P, Zhu Z, Lane M, Martinez D, Heitzeneder S, et al. Identification of GPC2 as an oncoprotein and candidate immunotherapeutic target in high-risk neuroblastoma. Cancer Cell. (2017) 32:295-309 e212. doi: 10.1016/j.ccell.2017.08.003

29. Hodi FS, O'day SJ, Mcdermott DF, Weber RW, Sosman JA, Haanen JB, et al. Improved survival with ipilimumab in patients with metastatic melanoma. $N$ Engl J Med. (2010) 363:711-23. doi: 10.1056/NEJMoa1003466

30. Brahmer JR, Tykodi SS, Chow LQ, Hwu WJ, Topalian SL, Hwu P, et al. Safety and activity of anti-PD-L1 antibody in patients with advanced cancer. $N$ Engl J Med. (2012) 366:2455-65. doi: 10.1056/NEJMoa1200694

31. Joshi S. Targeting the tumor microenvironment in neuroblastoma: recent advances and future directions. Cancer. (2020) 12:E2057. doi: 10.3390/cancers 12082057

32. Merchant MS, Wright M, Baird K, Wexler LH, Rodriguez-Galindo C, Bernstein D, et al. Phase I clinical trial of ipilimumab in pediatric patients with advanced solid tumors. Clin Cancer Res. (2016) 22:1364-70. doi: 10.1158/1078-0432.CCR-15-0491

33. Davis KL, Fox E, Reid JM, Liu X, Minard CG, Weigel B, et al. ADVL1412: Initial results of a phase I/II study of nivolumab and ipilimumab in pediatric patients with relapsed/refractory solid tumors-A COG study. J Clin Oncol. (2017) 35:10526. doi: 10.1200/JCO.2017.35.15_suppl.10526

34. Geoerger B, Kang HJ, Yalon-Oren M, Marshall LV, Vezina C, Pappo AS, et al. KEYNOTE-051: an update on the phase 2 results of pembrolizumab (pembro) in pediatric patients (pts) with advanced melanoma or a PD-L1positive advanced, relapsed or refractory solid tumor or lymphoma. J Clin Oncol. (2018) 36:10525. doi: 10.1200/JCO.2018.36.15_suppl.10525

35. Grobner SN, Worst BC, Weischenfeldt J, Buchhalter I, Kleinheinz K, Rudneva VA, et al. The landscape of genomic alterations across childhood cancers. Nature. (2018) 555:321-7. doi: 10.1038/nature25480 
36. Pistoia V, Morandi F, Bianchi G, Pezzolo A, Prigione I, Raffaghello L. Immunosuppressive microenvironment in neuroblastoma. Front Oncol. (2013) 3:167. doi: 10.3389/fonc.2013.00167

37. Koirala P, Roth ME, Gill J, Piperdi S, Chinai JM, Geller DS, et al. Immune infiltration and PD-L1 expression in the tumor microenvironment are prognostic in osteosarcoma. Sci Rep. (2016) 6:30093. doi: 10.1038/srep30093

38. Kabir TF, Chauhan A, Anthony L, Hildebrandt GC. Immune checkpoint inhibitors in pediatric solid tumors: status in 2018. Ochsner J. (2018) 18:3706. doi: 10.31486/toj.18.0055

39. Joshi S, Durden DL. Combinatorial approach to improve cancer immunotherapy: rational drug design strategy to simultaneously hit multiple targets to kill tumor cells and to activate the immune system. $J$ Oncol. (2019) 2019:5245034. doi: 10.1155/2019/5245034

40. Borriello L, Seeger RC, Asgharzadeh S, Declerck YA. More than the genes, the tumor microenvironment in neuroblastoma. Cancer Lett. (2016) 380:304-14. doi: 10.1016/j.canlet.2015.11.017

41. Pelizzo G, Veschi V, Mantelli M, Croce S, Di Benedetto V, D’angelo P, et al. Microenvironment in neuroblastoma: isolation and characterization of tumor-derived mesenchymal stromal cells. BMC Cancer. (2018) 18:1176. doi: 10.1186/s12885-018-5082-2

42. Vanichapol T, Chutipongtanate $S$, Anurathapan $U$, Hongeng $S$. Immune escape mechanisms and future prospects for immunotherapy in neuroblastoma. Biomed Res Int. (2018) 2018:1812535. doi: $10.1155 / 2018 / 1812535$

43. Lampson LA, Fisher CA, Whelan JP. Striking paucity of HLA-A, B, C and beta 2-microglobulin on human neuroblastoma cell lines. J Immunol. (1983) 130:2471-8.

44. Corrias MV, Occhino M, Croce M, De Ambrosis A, Pistillo MP, Bocca P, et al. Lack of HLA-class I antigens in human neuroblastoma cells: analysis of its relationship to TAP and tapasin expression. Tissue Antigens. (2001) 57:110-7. doi: 10.1034/j.1399-0039.2001.057002110.x

45. Prigione I, Corrias MV, Airoldi I, Raffaghello L, Morandi F, Bocca P, et al. Immunogenicity of human neuroblastoma. Ann N Y Acad Sci. (2004) 1028:69-80. doi: 10.1196/annals.1322.008

46. Wolfl M, Jungbluth AA, Garrido F, Cabrera T, Meyen-Southard S, Spitz $\mathrm{R}$, et al. Expression of MHC class I, MHC class II, and cancer germline antigens in neuroblastoma. Cancer Immunol Immunother. (2005) 54:400-6. doi: 10.1007/s00262-004-0603-z

47. Morandi F, Levreri I, Bocca P, Galleni B, Raffaghello L, Ferrone S, et al. Human neuroblastoma cells trigger an immunosuppressive program in monocytes by stimulating soluble HLA-G release. Cancer Res. (2007) 67:6433-41. doi: 10.1158/0008-5472.CAN-06-4588

48. Lorenzi S, Forloni M, Cifaldi L, Antonucci C, Citti A, Boldrini R, et al. IRF1 and NF-kB restore MHC class I-restricted tumor antigen processing and presentation to cytotoxic T cells in aggressive neuroblastoma. PLoS ONE. (2012) 7:e46928. doi: 10.1371/journal.pone.0046928

49. Morandi F, Scaruffi P, Gallo F, Stigliani S, Moretti S, Bonassi S, et al. Bone marrow-infiltrating human neuroblastoma cells express high levels of calprotectin and HLA-G proteins. PLoS ONE. (2012) 7:e29922. doi: 10.1371/journal.pone.0029922

50. Asgharzadeh S, Pique-Regi R, Sposto R, Wang H, Yang Y, Shimada H, et al. Prognostic significance of gene expression profiles of metastatic neuroblastomas lacking MYCN gene amplification. J Natl Cancer Inst. (2006) 98:1193-203. doi: 10.1093/jnci/djj330

51. Song L, Asgharzadeh S, Salo J, Engell K, Wu HW, Sposto R, et al. Valpha24-invariant NKT cells mediate antitumor activity via killing of tumor-associated macrophages. J Clin Invest. (2009) 119:1524-36. doi: 10.1172/JCI37869

52. Soldati R, Berger E, Zenclussen AC, Jorch G, Lode HN, Salatino M, et al. Neuroblastoma triggers an immunoevasive program involving galectin-1dependent modulation of $\mathrm{T}$ cell and dendritic cell compartments. Int $J$ Cancer. (2012) 131:1131-41. doi: 10.1002/ijc.26498

53. Lauder I, Aherne W. The significance of lymphocytic infiltration in neuroblastoma. Br J Cancer. (1972) 26:321-30. doi: 10.1038/bjc.1972.43

54. Carlson LM, Kogner P. Neuroblastoma-related inflammation: May small doses of aspirin be suitable for small cancer patients? Oncoimmunology. (2013) 2:e24658. doi: 10.4161/onci.24658
55. Mina M, Boldrini R, Citti A, Romania P, D'alicandro V, De Ioris $\mathrm{M}$, et al. Tumor-infiltrating $\mathrm{T}$ lymphocytes improve clinical outcome of therapy-resistant neuroblastoma. Oncoimmunology. (2015) 4:e1019981. doi: 10.1080/2162402X.2015.1019981

56. Mao Y, Eissler N, Blanc KL, Johnsen JI, Kogner P, Kiessling R. Targeting suppressive myeloid cells potentiates checkpoint inhibitors to control spontaneous neuroblastoma. Clin Cancer Res. (2016) 22:3849-59. doi: 10.1158/1078-0432.CCR-15-1912

57. Wang $M$, Yin B, Wang HY, Wang RF. Current advances in Tcell-based cancer immunotherapy. Immunotherapy. (2014) 6:1265-78. doi: 10.2217/imt.14.86

58. Xia A, Zhang Y, Xu J, Yin T, Lu XJ. T cell dysfunction in cancer immunity and immunotherapy. Front Immunol. (2019) 10:1719. doi: 10.3389/fimmu.2019.01719

59. Betof Warner A, Palmer JS, Shoushtari AN, Goldman DA, Panageas KS, Hayes SA, et al. Long-term outcomes and responses to retreatment in patients with melanoma treated with PD-1 blockade. J Clin Oncol. (2020) 38:1655-63. doi: 10.1200/JCO.19.01464

60. Blanc C, Hans S, Tran T, Granier C, Saldman A, Anson M, et al. Targeting resident memory T cells for cancer immunotherapy. Front Immunol. (2018) 9:1722. doi: 10.3389/fimmu.2018.01722

61. Nowicki TS, Hu-Lieskovan S, Ribas A. Mechanisms of resistance to PD-1 and PD-L1 blockade. Cancer J. (2018) 24:47-53. doi: 10.1097/PPO.0000000000000303

62. Gabrilovich DI, Nagaraj S. Myeloid-derived suppressor cells as regulators of the immune system. Nat Rev Immunol. (2009) 9:162-74. doi: $10.1038 /$ nri2506

63. Gabrilovich DI, Ostrand-Rosenberg S, Bronte V. Coordinated regulation of myeloid cells by tumours. Nat Rev Immunol. (2012) 12:253-68. doi: $10.1038 /$ nri3175

64. Metelitsa LS, Wu HW, Wang H, Yang Y, Warsi Z, Asgharzadeh S, et al. Natural killer T cells infiltrate neuroblastomas expressing the chemokine CCL2. J Exp Med. (2004) 199:1213-21. doi: 10.1084/jem.20031462

65. Hashimoto O, Yoshida M, Koma Y, Yanai T, Hasegawa D, Kosaka Y, et al. Collaboration of cancer-associated fibroblasts and tumour-associated macrophages for neuroblastoma development. J Pathol. (2016) 240:211-23. doi: $10.1002 /$ path.4769

66. Kumar V, Patel S, Tcyganov E, Gabrilovich DI. The nature of myeloid-derived suppressor cells in the tumor microenvironment. Trends Immunol. (2016) 37:208-20. doi: 10.1016/j.it.2016.01.004

67. Hadjidaniel MD, Muthugounder S, Hung LT, Sheard MA, Shirinbak S, Chan RY, et al. Tumor-associated macrophages promote neuroblastoma via STAT3 phosphorylation and up-regulation of c-MYC. Oncotarget. (2017) 8:91516-29. doi: 10.18632/oncotarget.21066

68. Gowda M, Godder K, Kmieciak M, Worschech A, Ascierto ML, Wang E, et al. Distinct signatures of the immune responses in low risk versus high risk neuroblastoma. J Transl Med. (2011) 9:170. doi: 10.1186/1479-5876-9-170

69. Gabrilovich DI. Myeloid-derived suppressor cells. Cancer Immunol Res. (2017) 5:3-8. doi: 10.1158/2326-6066.CIR-16-0297

70. Cheng P, Corzo CA, Luetteke N, Yu B, Nagaraj S, Bui MM, et al. Inhibition of dendritic cell differentiation and accumulation of myeloidderived suppressor cells in cancer is regulated by S100A9 protein. J Exp Med. (2008) 205:2235-49. doi: 10.1084/jem.20080132

71. Greifenberg V, Ribechini E, Rossner S, Lutz MB. Myeloid-derived suppressor cell activation by combined LPS and IFN-gamma treatment impairs DC development. Eur J Immunol. (2009) 39:2865-76. doi: 10.1002/eji.200939486

72. Corzo CA, Condamine T, Lu L, Cotter MJ, Youn JI, Cheng P, et al. HIFlalpha regulates function and differentiation of myeloid-derived suppressor cells in the tumor microenvironment. J Exp Med. (2010) 207:2439-53. doi: $10.1084 /$ jem.20100587

73. Santilli G, Piotrowska I, Cantilena S, Chayka O, D'alicarnasso M, Morgenstern DA, et al. Polyphenon [corrected] E enhances the antitumor immune response in neuroblastoma by inactivating myeloid suppressor cells. Clin Cancer Res. (2013) 19:1116-25. doi: 10.1158/1078-0432.CCR12-2528

74. Bianchi G, Vuerich M, Pellegatti P, Marimpietri D, Emionite L, Marigo I, et al. ATP/P2X7 axis modulates myeloid-derived suppressor cell functions 
in neuroblastoma microenvironment. Cell Death Dis. (2014) 5:e1135. doi: 10.1038/cddis.2014.109

75. Reynolds CP, Matthay KK, Villablanca JG, Maurer BJ. Retinoid therapy of high-risk neuroblastoma. Cancer Lett. (2003) 197:185-92. doi: 10.1016/S0304-3835(03)00108-3

76. Villablanca JG, Khan AA, Avramis VI, Seeger RC, Matthay KK, Ramsay NK, et al. Phase I trial of 13-cis-retinoic acid in children with neuroblastoma following bone marrow transplantation. J Clin Oncol. (1995) 13:894-901. doi: 10.1200/JCO.1995.13.4.894

77. Khan AA, Villablanca JG, Reynolds CP, Avramis VI. Pharmacokinetic studies of 13-cis-retinoic acid in pediatric patients with neuroblastoma following bone marrow transplantation. Cancer Chemother Pharmacol. (1996) 39:3441. doi: $10.1007 / \mathrm{s} 002800050535$

78. Matthay KK, Villablanca JG, Seeger RC, Stram DO, Harris RE, Ramsay NK, et al. Treatment of high-risk neuroblastoma with intensive chemotherapy, radiotherapy, autologous bone marrow transplantation, and 13-cis-retinoic acid. Children's Cancer Group. N Engl J Med. (1999) 341:1165-73. doi: 10.1056/NEJM199910143411601

79. Adamson PC, Reaman G, Finklestein JZ, Feusner J, Berg SL, Blaney SM, et al. Phase I trial and pharmacokinetic study of all-trans-retinoic acid administered on an intermittent schedule in combination with interferonalpha2a in pediatric patients with refractory cancer. J Clin Oncol. (1997) 15:3330-7. doi: 10.1200/JCO.1997.15.11.3330

80. Adamson PC, Matthay KK, O'brien M, Reaman GH, Sato JK, Balis FM. A phase 2 trial of all-trans-retinoic acid in combination with interferonalpha2a in children with recurrent neuroblastoma or Wilms tumor: a pediatric oncology branch, NCI and Children's Oncology Group Study. Pediatr Blood Cancer. (2007) 49:661-5. doi: 10.1002/pbc.21011

81. Modak S, Kushner BH, Basu E, Roberts SS, Cheung NK. Combination of bevacizumab, irinotecan, and temozolomide for refractory or relapsed neuroblastoma: results of a phase II study. Pediatr Blood Cancer. (2017) 64. doi: $10.1002 / p b c .26448$

82. Moreno L, Moroz V, Owens C, Valteau-Couanet D, Gambart M, Castel $\mathrm{V}$, et al. Bevacizumab for children with relapsed \&amp; refractory highrisk neuroblastoma (RR-HRNB): Results of the BEACON-neuroblastoma randomized phase II trial - A European ITCC-SIOPEN trial. Ann Oncol. (2019) 30:v901. doi: 10.1093/annonc/mdz394.061

83. Johnson $\mathrm{BD}$, Jing $\mathrm{W}$, Orentas RJ. CD25+ regulatory $\mathrm{T}$ cell inhibition enhances vaccine-induced immunity to neuroblastoma. I Immunother. (2007) 30:203-14. doi: 10.1097/01.cji.0000211336.91513.dd

84. Jing W, Yan X, Hallett WH, Gershan JA, Johnson BD. Depletion of CD25(+) $\mathrm{T}$ cells from hematopoietic stem cell grafts increases posttransplantation vaccine-induced immunity to neuroblastoma. Blood. (2011) 117:6952-62. doi: 10.1182/blood-2010-12-326108

85. Rigo V, Corrias MV, Orengo AM, Brizzolara A, Emionite L, Fenoglio D, et al. Recombinant IL-21 and anti-CD4 antibodies cooperate in syngeneic neuroblastoma immunotherapy and mediate long-lasting immunity. Cancer Immunol Immunother. (2014) 63:501-11. doi: 10.1007/s00262-014-1536-9

86. Tilak T, Sherawat S, Agarwala S, Gupta R, Vishnubhatla S, Bakhshi S. Circulating T-regulatory cells in neuroblastoma: a pilot prospective study. Pediatr Hematol Oncol. (2014) 31:717-22. doi: $10.3109 / 08880018.2014 .886002$

87. Morandi F, Croce M, Cangemi G, Barco S, Rigo V, Carlini B, et al. IL-10 and ARG-1 concentrations in bone marrow and peripheral blood of metastatic neuroblastoma patients do not associate with clinical outcome. J Immunol Res. (2015) 2015:718975. doi: 10.1155/2015/718975

88. Morandi F, Pozzi S, Barco S, Cangemi G, Amoroso L, Carlini B, et al. CD4(+)CD25(hi)CD127(-) Treg and CD4(+)CD45R0(+)CD49b(+)LAG3(+) Tr1 cells in bone marrow and peripheral blood samples from children with neuroblastoma. Oncoimmunology. (2016) 5:e1249553. doi: 10.1080/2162402X.2016.1249553

89. Chen Y, Zhang X. Pivotal regulators of tissue homeostasis and cancer: macrophages. Exp Hematol Oncol. (2017) 6:23. doi: 10.1186/s40164-017-0083-4

90. Gordon S, Martinez FO. Alternative activation of macrophages: mechanism and functions. Immunity. (2010) 32:593-604. doi: 10.1016/j.immuni.2010.05.007
91. Martinez FO, Gordon S, Locati M, Mantovani A. Transcriptional profiling of the human monocyte-to-macrophage differentiation and polarization: new molecules and patterns of gene expression. J Immunol. (2006) 177:7303-11. doi: 10.4049/jimmunol.177.10.7303

92. Jablonski KA, Amici SA, Webb LM, Ruiz-Rosado Jde D, Popovich PG, Partida-Sanchez S, et al. Novel Markers to Delineate Murine M1 and M2 Macrophages. PLoS ONE. (2015) 10:e0145342. doi: 10.1371/journal.pone.0145342

93. Orecchioni M, Ghosheh Y, Pramod AB, Ley K. Macrophage Polarization: Different Gene Signatures in M1(LPS+) vs. Classically and M2(LPS-) vs. Alternatively Activated Macrophages. Front Immunol. (2019) 10:1084. doi: 10.3389/fimmu.2019.01084

94. Rath M, Muller I, Kropf P, Closs EI, Munder M. Metabolism via arginase or nitric oxide synthase: two competing arginine pathways in macrophages. Front Immunol. (2014) 5:532. doi: 10.3389/fimmu.2014.00532

95. Viola A, Munari F, Sanchez-Rodriguez R, Scolaro T, Castegna A. The metabolic signature of macrophage responses. Front Immunol. (2019) 10:1462. doi: 10.3389/fimmu.2019.01462

96. Ishii M, Wen H, Corsa CA, Liu T, Coelho AL, Allen RM, et al. Epigenetic regulation of the alternatively activated macrophage phenotype. Blood. (2009) 114:3244-54. doi: 10.1182/blood-2009-04-217620

97. Takeuch O, Akira S. Epigenetic control of macrophage polarization. Eur $J$ Immunol. (2011) 41:2490-3. doi: 10.1002/eji.201141792

98. Mosser DM, Edwards JP. Exploring the full spectrum of macrophage activation. Nat Rev Immunol. (2008) 8:958-69. doi: 10.1038/nri2448

99. Mantovani A, Sica A, Sozzani S, Allavena P, Vecchi A, Locati M. The chemokine system in diverse forms of macrophage activation and polarization. Trends Immunol. (2004) 25:677-86. doi: 10.1016/j.it.2004.09.015

100. Manjili MH, Egilmez N, Knutson KL, Selvan SR, Ostberg JR. Tumor escape and progression under immune pressure. Clin Dev Immunol. (2012) 2012:641079. doi: $10.1155 / 2012 / 641079$

101. Wang LX, Zhang SX, Wu HJ, Rong XL, Guo J. M2b macrophage polarization and its roles in diseases. J Leukoc Biol. (2019) 106:345-58. doi: 10.1002/JLB.3RU1018-378RR

102. Edwards JP, Zhang X, Frauwirth KA, Mosser DM. Biochemical and functional characterization of three activated macrophage populations. $J$ Leukoc Biol. (2006) 80:1298-307. doi: 10.1189/jlb.0406249

103. Rodriguez-Prados JC, Traves PG, Cuenca J, Rico D, Aragones J, MartinSanz P, et al. Substrate fate in activated macrophages: a comparison between innate, classic, and alternative activation. J Immunol. (2010) 185:605-14. doi: $10.4049 /$ jimmunol.0901698

104. Chanmee T, Ontong P, Konno K, Itano N. Tumor-associated macrophages as major players in the tumor microenvironment. Cancers. (2014) 6:1670-90. doi: $10.3390 /$ cancers 6031670

105. Laoui D, Van Overmeire E, Di Conza G, Aldeni C, Keirsse J, Morias Y, et al. Tumor hypoxia does not drive differentiation of tumor-associated macrophages but rather fine-tunes the M2-like macrophage population. Cancer Res. (2014) 74:24-30. doi: 10.1158/0008-5472.CAN-13-1196

106. Laoui D, Movahedi K, Van Overmeire E, Van Den Bossche J, Schouppe E, Mommer C, et al. Tumor-associated macrophages in breast cancer: distinct subsets, distinct functions. Int J Dev Biol. (2011) 55:861-7. doi: $10.1387 / \mathrm{ijdb} .113371 \mathrm{dl}$

107. Laoui D, Van Overmeire E, Movahedi K, Van Den Bossche J, Schouppe E, Mommer C, et al. Mononuclear phagocyte heterogeneity in cancer: different subsets and activation states reaching out at the tumor site. Immunobiology. (2011) 216:1192-202. doi: 10.1016/j.imbio.2011.06.007

108. Schouppe E, De Baetselier P, Van Ginderachter JA, Sarukhan A. Instruction of myeloid cells by the tumor microenvironment: open questions on the dynamics and plasticity of different tumor-associated myeloid cell populations. Oncoimmunology. (2012) 1:1135-45. doi: 10.4161/onci.21566

109. Cassidy JW, Caldas C, Bruna A. Maintaining tumor heterogeneity in patient-derived tumor xenografts. Cancer Res. (2015) 75:2963-8. doi: 10.1158/0008-5472.CAN-15-0727

110. Mantovani A, Marchesi F, Malesci A, Laghi L, Allavena P. Tumour-associated macrophages as treatment targets in oncology. Nat Rev Clin Oncol. (2017) 14:399-416. doi: 10.1038/nrclinonc.2016.217 
111. Jayasingam SD, Citartan M, Thang TH, Mat Zin AA, Ang KC, Ch'ng ES. Evaluating the polarization of tumor-associated macrophages into M1 and M2 phenotypes in human cancer tissue: technicalities and challenges in routine clinical practice. Front Oncol. (2019) 9:1512. doi: $10.3389 /$ fonc. 2019.01512

112. Yang L, Zhang Y. Tumor-associated macrophages: from basic research to clinical application. J Hematol Oncol. (2017) 10:58. doi: 10.1186/s13045-0170430-2

113. Nickerson HJ, Matthay KK, Seeger RC, Brodeur GM, Shimada H, Perez C, et al. Favorable biology and outcome of stage IV-S neuroblastoma with supportive care or minimal therapy: a Children's Cancer Group study. J Clin Oncol. (2000) 18:477-86. doi: 10.1200/JCO.2000.18.3.477

114. Schleiermacher G, Rubie H, Hartmann O, Bergeron C, Chastagner P, Mechinaud F, et al. Treatment of stage 4 s neuroblastoma-report of 10 years' experience of the French Society of Paediatric Oncology (SFOP). Br J Cancer. (2003) 89:470-6. doi: 10.1038/sj.bjc.6601154

115. Fultang L, Gamble LD, Gneo L, Berry AM, Egan SA, De Bie F, et al. Macrophage-Derived ILlbeta and TNFalpha regulate arginine metabolism in neuroblastoma. Cancer Res. (2019) 79:611-24. doi: 10.1158/0008-5472.CAN-18-2139

116. Ruffell B, Coussens LM. Macrophages and therapeutic resistance in cancer. Cancer Cell. (2015) 27:462-72. doi: 10.1016/j.ccell.2015. 02.015

117. Ribatti D, Vacca A, Nico B, De Falco G, Giuseppe Montaldo P, Ponzoni M. Angiogenesis and anti-angiogenesis in neuroblastoma. Eur J Cancer. (2002) 38:750-7. doi: 10.1016/S0959-8049(01)00337-9

118. Wyckoff JB, Wang Y, Lin EY, Li JF, Goswami S, Stanley ER, et al. Direct visualization of macrophage-assisted tumor cell intravasation in mammary tumors. Cancer Res. (2007) 67:2649-56. doi: 10.1158/0008-5472.CAN-06-1823

119. Lofstedt T, Fredlund E, Holmquist-Mengelbier L, Pietras A, Ovenberger M, Poellinger L, et al. Hypoxia inducible factor-2alpha in cancer. Cell Cycle. (2007) 6:919-26. doi: 10.4161/cc.6.8.4133

120. Pietras A, Gisselsson D, Ora I, Noguera R, Beckman S, Navarro S, et al. High levels of HIF-2alpha highlight an immature neural crest-like neuroblastoma cell cohort located in a perivascular niche. J Pathol. (2008) 214:482-8. doi: 10.1002/path.2304

121. Abraham D, Zins K, Sioud M, Lucas T, Schafer R, Stanley ER, et al. Stromal cell-derived CSF-1 blockade prolongs xenograft survival of CSF-1negative neuroblastoma. Int J Cancer. (2010) 126:1339-52. doi: 10.1002/ijc. 24859

122. Webb MW, Sun J, Sheard MA, Liu WY, Wu HW, Jackson JR, et al. Colony stimulating factor 1 receptor blockade improves the efficacy of chemotherapy against human neuroblastoma in the absence of $\mathrm{T}$ lymphocytes. Int J Cancer. (2018) 143:1483-93. doi: 10.1002/ijc.31532

123. Eubank TD, Galloway M, Montague CM, Waldman WJ, Marsh CB. M-CSF induces vascular endothelial growth factor production and angiogenic activity from human monocytes. J Immunol. (2003) 171:2637-43. doi: 10.4049/jimmunol.171.5.2637

124. Imtiyaz HZ, Williams EP, Hickey MM, Patel SA, Durham AC, Yuan LJ, et al. Hypoxia-inducible factor 2alpha regulates macrophage function in mouse models of acute and tumor inflammation. J Clin Invest. (2010) 120:2699-714. doi: 10.1172/JCI39506

125. Kumar V, Gabrilovich DI. Hypoxia-inducible factors in regulation of immune responses in tumour microenvironment. Immunology. (2014) 143:512-9. doi: $10.1111 /$ imm. 12380

126. Xu W, Liu LZ, Loizidou M, Ahmed M, Charles IG. The role of nitric oxide in cancer. Cell Res. (2002) 12:311-20. doi: 10.1038/sj.cr.7290133

127. Perrotta C, Cervia D, Di Renzo I, Moscheni C, Bassi MT, Campana L, et al. Nitric Oxide generated by tumor-associated macrophages is responsible for cancer resistance to cisplatin and correlated with syntaxin 4 and acid sphingomyelinase inhibition. Front Immunol. (2018) 9:1186. doi: 10.3389/fimmu.2018.01186

128. Holotiuk VV, Kryzhanivska AY, Churpiy IK, Tataryn BB, Ivasiutyn DY. Role of nitric oxide in pathogenesis of tumor growth and its possible application in cancer treatment. Exp Oncol. (2019) 41:210-5. doi: 10.32471/exp-oncology.2312-8852.vol-41-no-3.13515
129. Joshi S, Singh AR, Durden DL. MDM2 regulates hypoxic hypoxiainducible factor 1alpha stability in an E3 ligase, proteasome, and PTENphosphatidylinositol 3-kinase-AKT-dependent manner. J Biol Chem. (2014) 289:22785-97. doi: 10.1074/jbc.M114.587493

130. Joshi S, Singh AR, Zulcic M, Bao L, Messer K, Ideker T, et al. Rac2 controls tumor growth, metastasis and M1-M2 macrophage differentiation in vivo. PLoS ONE. (2014) 9:e95893. doi: 10.1371/journal.pone.0095893

131. Joshi S, Singh AR, Zulcic M, Durden DL. A macrophage-dominant PI3K isoform controls hypoxia-induced HIF1alpha and HIF2alpha stability and tumor growth, angiogenesis, and metastasis. Mol Cancer Res. (2014) 12:1520-31. doi: 10.1158/1541-7786.MCR-13-0682

132. Joshi S, Liu KX, Zulcic M, Singh AR, Skola D, Glass CK, et al. Macrophage Syk-PI3Kgamma inhibits antitumor immunity: SRX3207, a Novel Dual SykPI3K inhibitory chemotype relieves tumor immunosuppression. Mol Cancer Ther. (2020) 19:755-64. doi: 10.1158/1535-7163.MCT-19-0947

133. Erdreich-Epstein A, Shimada H, Groshen S, Liu M, Metelitsa LS, Kim $\mathrm{KS}$, et al. Integrins alpha(v)beta 3 and alpha(v)beta5 are expressed by endothelium of high-risk neuroblastoma and their inhibition is associated with increased endogenous ceramide. Cancer Res. (2000) 60:712-21.

134. Andrews FH, Singh AR, Joshi S, Smith CA, Morales GA, Garlich JR, et al. Dual-activity PI3K-BRD4 inhibitor for the orthogonal inhibition of MYC to block tumor growth and metastasis. Proc Natl Acad Sci USA. (2017) 114:E1072-80. doi: 10.1073/pnas.1613091114

135. Joshi S, Singh AR, Liu KX, Pham TV, Zulcic M, Skola D, et al. SF2523: Dual PI3K/BRD4 inhibitor blocks tumor immunosuppression and promotes adaptive immune responses in cancer. Mol Cancer Ther. (2019) 18:1036-44. doi: 10.1158/1535-7163.MCT-18-1206

136. Komohara Y, Takeya M. CAFs and TAMs: maestros of the tumour microenvironment. J Pathol. (2017) 241:313-5. doi: 10.1002/path.4824

137. Orimo A, Gupta PB, Sgroi DC, Arenzana-Seisdedos F, Delaunay T, Naeem $\mathrm{R}$, et al. Stromal fibroblasts present in invasive human breast carcinomas promote tumor growth and angiogenesis through elevated SDF-1/CXCL12 secretion. Cell. (2005) 121:335-48. doi: 10.1016/j.cell.2005.02.034

138. Silzle T, Kreutz M, Dobler MA, Brockhoff G, Knuechel R, Kunz-Schughart LA. Tumor-associated fibroblasts recruit blood monocytes into tumor tissue. Eur J Immunol. (2003) 33:1311-20. doi: 10.1002/eji.200323057

139. Comito G, Giannoni E, Segura CP, Barcellos-De-Souza P, Raspollini MR, Baroni G, et al. Cancer-associated fibroblasts and M2-polarized macrophages synergize during prostate carcinoma progression. Oncogene. (2014) 33:242331. doi: 10.1038/onc.2013.191

140. Xu Y, Sun J, Sheard MA, Tran HC, Wan Z, Liu WY, et al. Lenalidomide overcomes suppression of human natural killer cell anti-tumor functions by neuroblastoma microenvironment-associated IL- 6 and TGFbeta1. Cancer Immunol Immunother. (2013) 62:1637-48. doi: 10.1007/s00262-013-1466-y

141. Tageja N. Lenalidomide - current understanding of mechanistic properties. Anticancer Agents Med Chem. (2011) 11:315-26. doi: $10.2174 / 187152011795347487$

142. Mcdaniel JM, Pinilla-Ibarz J, Epling-Burnette PK. Molecular action of lenalidomide in lymphocytes and hematologic malignancies. Adv Hematol. (2012) 2012:513702. doi: $10.1155 / 2012 / 513702$

143. Liu D, Song L, Wei J, Courtney AN, Gao X, Marinova E, et al. IL15 protects NKT cells from inhibition by tumor-associated macrophages and enhances antimetastatic activity. J Clin Invest. (2012) 122:2221-33. doi: 10.1172/JCI59535

144. Peranzoni E, Lemoine J, Vimeux L, Feuillet V, Barrin S, Kantari-Mimoun $\mathrm{C}$, et al. Macrophages impede CD8 T cells from reaching tumor cells and limit the efficacy of anti-PD-1 treatment. Proc Natl Acad Sci USA. (2018) 115:E4041-50. doi: 10.1073/pnas.1720948115

145. Vitale I, Manic G, Coussens LM, Kroemer G, Galluzzi L. Macrophages and metabolism in the tumor microenvironment. Cell Metab. (2019) 30:36-50. doi: 10.1016/j.cmet.2019.06.001

146. O’neill LA, Kishton RJ, Rathmell J. A guide to immunometabolism for immunologists. Nat Rev Immunol. (2016) 16:553-65. doi: 10.1038/nri.2016.70

147. Bantug GR, Galluzzi L, Kroemer G, Hess C. The spectrum of T cell metabolism in health and disease. Nat Rev Immunol. (2018) 18:19-34. doi: $10.1038 /$ nri.2017.99 
148. Noman MZ, Desantis G, Janji B, Hasmim M, Karray S, Dessen P, et al. PDL1 is a novel direct target of HIF-1alpha, and its blockade under hypoxia enhanced MDSC-mediated T cell activation. J Exp Med. (2014) 211:781-90. doi: 10.1084/jem.20131916

149. Chang CH, Qiu J, O'sullivan D, Buck MD, Noguchi T, Curtis JD, et al. Metabolic competition in the tumor microenvironment is a driver of cancer progression. Cell. (2015) 162:1229-41. doi: 10.1016/j.cell.2015.08.016

150. Zheng X, Turkowski K, Mora J, Brune B, Seeger W, Weigert A, et al. Redirecting tumor-associated macrophages to become tumoricidal effectors as a novel strategy for cancer therapy. Oncotarget. (2017) 8:48436-52. doi: 10.18632/oncotarget.17061

151. Sohara Y, Shimada H, Scadeng M, Pollack H, Yamada S, Ye W, et al. Lytic bone lesions in human neuroblastoma xenograft involve osteoclast recruitment and are inhibited by bisphosphonate. Cancer Res. (2003) 63:3026-31.

152. Wu W, Luo Y, Sun C, Liu Y, Kuo P, Varga J, et al. Targeting cellimpermeable prodrug activation to tumor microenvironment eradicates multiple drug-resistant neoplasms. Cancer Res. (2006) 66:970-80. doi: 10.1158/0008-5472.CAN-05-2591

153. D’incalci M, Colombo T, Ubezio P, Nicoletti I, Giavazzi R, Erba $\mathrm{E}$, et al. The combination of yondelis and cisplatin is synergistic against human tumor xenografts. Eur J Cancer. (2003) 39:1920-6. doi: 10.1016/S0959-8049(03)00490-8

154. Germano G, Frapolli R, Belgiovine C, Anselmo A, Pesce S, Liguori M, et al. Role of macrophage targeting in the antitumor activity of trabectedin. Cancer Cell. (2013) 23:249-62. doi: 10.1016/j.ccr.2013.01.008

155. Puissant A, Frumm SM, Alexe G, Bassil CF, Qi J, Chanthery YH, et al. Targeting MYCN in neuroblastoma by BET bromodomain inhibition. Cancer Discov. (2013) 3:308-23. doi: 10.1158/2159-8290.CD-12-0418

156. Wyce A, Ganji G, Smitheman KN, Chung CW, Korenchuk S, Bai Y, et al. BET inhibition silences expression of MYCN and BCL2 and induces cytotoxicity in neuroblastoma tumor models. PLoS ONE. (2013) 8:e72967. doi: 10.1371/journal.pone.0072967

157. Kroesen M, Bull C, Gielen PR, Brok IC, Armandari I, Wassink M, et al. Anti-GD2 mAb and Vorinostat synergize in the treatment of neuroblastoma. Oncoimmunology. (2016) 5:e1164919. doi: 10.1080/2162402X.2016.1164919

158. Buhtoiarov IN, Lum HD, Berke G, Sondel PM, Rakhmilevich AL. Synergistic activation of macrophages via CD40 and TLR9 results in $\mathrm{T}$ cell independent antitumor effects. J Immunol. (2006) 176:309-18. doi: 10.4049/jimmunol.176.1.309

159. Luheshi N, Davies G, Legg J. Understanding the influence of the tumor microenvironment on macrophage responses to CD40 agonists. Oncoimmunology. (2014) 3:e27615. doi: 10.4161/onci.27615

160. Voeller J, Erbe AK, Slowinski J, Rasmussen K, Carlson PM, Hoefges A, et al. Combined innate and adaptive immunotherapy overcomes resistance of immunologically cold syngeneic murine neuroblastoma to checkpoint inhibition. J Immunother Cancer. (2019) 7:344. doi: 10.1186/s40425-019-0823-6

161. Noy R, Pollard JW. Tumor-associated macrophages: from mechanisms to therapy. Immunity. (2014) 41:49-61. doi: 10.1016/j.immuni.2014.06.010

162. Ries CH, Cannarile MA, Hoves S, Benz J, Wartha K, Runza V, et al. Targeting tumor-associated macrophages with anti-CSF-1R antibody reveals a strategy for cancer therapy. Cancer Cell. (2014) 25:846-59. doi: 10.1016/j.ccr.2014.05.016

163. Cassier PA, Italiano A, Gomez-Roca CA, Le Tourneau C, Toulmonde M, Cannarile MA, et al. CSF1R inhibition with emactuzumab in locally advanced diffuse-type tenosynovial giant cell tumours of the soft tissue: a dose-escalation and dose-expansion phase 1 study. Lancet Oncol. (2015) 16:949-56. doi: 10.1016/S1470-2045(15)00132-1

164. Gomez-Roca CA, Italiano A, Le Tourneau C, Cassier PA, Toulmonde $\mathrm{M}$, D'angelo SP, et al. Phase I study of emactuzumab single agent or in combination with paclitaxel in patients with advanced/metastatic solid tumors reveals depletion of immunosuppressive M2-like macrophages. Ann Oncol. (2019) 30:1381-92. doi: 10.1093/annonc/mdz163

165. Tap WD, Gelderblom H, Palmerini E, Desai J, Bauer S, Blay JY, et al. Pexidartinib versus placebo for advanced tenosynovial giant cell tumour (ENLIVEN): a randomised phase 3 trial. Lancet. (2019) 394:478-87. doi: 10.1016/S0140-6736(19)30764-0
166. Stafford JH, Hirai T, Deng L, Chernikova SB, Urata K, West BL, et al. Colony stimulating factor 1 receptor inhibition delays recurrence of glioblastoma after radiation by altering myeloid cell recruitment and polarization. Neuro Oncol. (2016) 18:797-806. doi: 10.1093/neuonc/nov272

167. Pyonteck SM, Akkari L, Schuhmacher AJ, Bowman RL, Sevenich L, Quail DF, et al. CSF-1R inhibition alters macrophage polarization and blocks glioma progression. Nat Med. (2013) 19:1264-72. doi: 10.1038/nm.3337

168. Qian BZ, Li J, Zhang H, Kitamura T, Zhang J, Campion LR, et al. CCL2 recruits inflammatory monocytes to facilitate breast-tumour metastasis. Nature. (2011) 475:222-5. doi: 10.1038/nature10138

169. Sanford DE, Belt BA, Panni RZ, Mayer A, Deshpande AD, Carpenter D, et al. Inflammatory monocyte mobilization decreases patient survival in pancreatic cancer: a role for targeting the CCL2/CCR2 axis. Clin Cancer Res. (2013) 19:3404-15. doi: 10.1158/1078-0432.CCR-13-0525

170. Pienta KJ, Machiels JP, Schrijvers D, Alekseev B, Shkolnik M, Crabb SJ, et al. Phase 2 study of carlumab (CNTO 888), a human monoclonal antibody against CC-chemokine ligand 2 (CCL2), in metastatic castration-resistant prostate cancer. Invest New Drugs. (2013) 31:760-8. doi: 10.1007/s10637-012-9869-8

171. Sandhu SK, Papadopoulos K, Fong PC, Patnaik A, Messiou C, Olmos D, et al. A first-in-human, first-in-class, phase I study of carlumab (CNTO 888), a human monoclonal antibody against CC-chemokine ligand 2 in patients with solid tumors. Cancer Chemother Pharmacol. (2013) 71:104150. doi: 10.1007/s00280-013-2099-8

172. Li MH, Harel M, Hla T, Ferrer F. Induction of chemokine (C-C motif) ligand 2 by sphingosine-1-phosphate signaling in neuroblastoma. J Pediatr Surg. (2014) 49:1286-91. doi: 10.1016/j.jpedsurg.2014.04.001

173. Li MH, Swenson R, Harel M, Jana S, Stolarzewicz E, Hla T, et al. Antitumor activity of a novel sphingosine-1-phosphate 2 antagonist, AB1, in neuroblastoma. J Pharmacol Exp Ther. (2015) 354:261-8. doi: $10.1124 /$ jpet.115.224519

174. Germano G, Frapolli R, Simone M, Tavecchio M, Erba E, Pesce S, et al. Antitumor and anti-inflammatory effects of trabectedin on human myxoid liposarcoma cells. Cancer Res. (2010) 70:2235-44. doi: 10.1158/0008-5472.CAN-09-2335

175. Mcewen-Smith RM, Salio M, Cerundolo V. CD1d-dependent endogenous and exogenous lipid antigen presentation. Curr Opin Immunol. (2015) 34:116-25. doi: 10.1016/j.coi.2015.03.004

176. Van Kaer L, Parekh VV, Wu L. The response of CD1d-restricted invariant NKT cells to microbial pathogens and their products. Front Immunol. (2015) 6:226. doi: 10.3389/fimmu.2015.00226

177. Metelitsa LS, Naidenko OV, Kant A, Wu HW, Loza MJ, Perussia B, et al. Human NKT cells mediate antitumor cytotoxicity directly by recognizing target cell CD1d with bound ligand or indirectly by producing IL-2 to activate NK cells. J Immunol. (2001) 167:3114-22. doi: 10.4049/jimmunol.167.6.3114

178. Lastres P, Bellon T, Cabanas C, Sanchez-Madrid F, Acevedo A, Gougos A, et al. Regulated expression on human macrophages of endoglin, an Arg-Gly-Asp-containing surface antigen. Eur J Immunol. (1992) 22:393-7. doi: 10.1002/eji.1830220216

179. Johann PD, Vaegler M, Gieseke F, Mang P, Armeanu-Ebinger S, Kluba T, et al. Tumour stromal cells derived from paediatric malignancies display MSClike properties and impair NK cell cytotoxicity. BMC Cancer. (2010) 10:501. doi: 10.1186/1471-2407-10-501

180. Paauwe M, Heijkants RC, Oudt CH, Van Pelt GW, Cui C, Theuer CP, et al. Endoglin targeting inhibits tumor angiogenesis and metastatic spread in breast cancer. Oncogene. (2016) 35:4069-79. doi: 10.1038/onc.2015.509

181. Borriello L, Nakata R, Sheard MA, Fernandez GE, Sposto R, Malvar J, et al. Cancer-associated fibroblasts share characteristics and protumorigenic activity with mesenchymal stromal cells. Cancer Res. (2017) 77:5142-57. doi: 10.1158/0008-5472.CAN-16-2586

182. Wu HW, Sheard MA, Malvar J, Fernandez GE, Declerck YA, Blavier L, et al. Anti-CD105 antibody eliminates tumor microenvironment cells and enhances anti-GD2 antibody immunotherapy of neuroblastoma with activated natural killer cells. Clin Cancer Res. (2019) 25:4761-74. doi: 10.1158/1078-0432.CCR-18-3358

183. Peng H, Sohara Y, Moats RA, Nelson MD Jr, Groshen SG, Ye W, et al. The activity of zoledronic Acid on neuroblastoma bone metastasis involves 
inhibition of osteoclasts and tumor cell survival and proliferation. Cancer Res. (2007) 67:9346-55. doi: 10.1158/0008-5472.CAN-06-4508

184. Backman U, Svensson A, Christofferson RH, Azarbayjani F. The bisphosphonate, zoledronic acid reduces experimental neuroblastoma growth by interfering with tumor angiogenesis. Anticancer Res. (2008) 28:1551-7.

185. Russell HV, Groshen SG, Ara T, Declerck YA, Hawkins R, Jackson HA, et al. A phase I study of zoledronic acid and low-dose cyclophosphamide in recurrent/refractory neuroblastoma: a new approaches to neuroblastoma therapy (NANT) study. Pediatr Blood Cancer. (2011) 57:275-82. doi: $10.1002 / \mathrm{pbc} .22821$

186. Zeisberger SM, Odermatt B, Marty C, Zehnder-Fjallman AH, Ballmer-Hofer $\mathrm{K}$, Schwendener RA. Clodronate-liposome-mediated depletion of tumourassociated macrophages: a new and highly effective antiangiogenic therapy approach. Br J Cancer. (2006) 95:272-81. doi: 10.1038/sj.bjc.6603240

187. Vorotnjak M, Boos J, Lanvers-Kaminsky C. In vitro toxicity of bisphosphonates on human neuroblastoma cell lines. Anticancer Drugs. (2004) 15:795-802. doi: 10.1097/00001813-200409000-00009

188. Perry CM, Figgitt DP. Zoledronic acid: a review of its use in patients with advanced cancer. Drugs. (2004) 64:1197-211. doi: 10.2165/00003495-200464110-00004

189. Luo Y, Zhou H, Krueger J, Kaplan C, Lee SH, Dolman C, et al. Targeting tumor-associated macrophages as a novel strategy against breast cancer. $J$ Clin Invest. (2006) 116:2132-41. doi: 10.1172/JCI27648

190. Sica A, Larghi P, Mancino A, Rubino L, Porta C, Totaro MG, et al. Macrophage polarization in tumour progression. Semin Cancer Biol. (2008) 18:349-55. doi: 10.1016/j.semcancer.2008.03.004

191. Fletcher JS, Springer MG, Choi K, Jousma E, Rizvi TA, Dombi E, et al. STAT3 inhibition reduces macrophage number and tumor growth in neurofibroma. Oncogene. (2019) 38:2876-84. doi: 10.1038/s41388-018-0600-x

192. Buhtoiarov IN, Lum H, Berke G, Paulnock DM, Sondel PM, Rakhmilevich AL. CD40 ligation activates murine macrophages via an IFN-gammadependent mechanism resulting in tumor cell destruction in vitro. $J$ Immunol. (2005) 174:6013-22. doi: 10.4049/jimmunol.174.10.6013

193. Rakhmilevich AL, Alderson KL, Sondel PM. T-cell-independent antitumor effects of CD40 ligation. Int Rev Immunol. (2012) 31:267-78. doi: 10.3109/08830185.2012.698337

194. Lum HD, Buhtoiarov IN, Schmidt BE, Berke G, Paulnock DM, Sondel $\mathrm{PM}$, et al. In vivo CD40 ligation can induce T-cell-independent antitumor effects that involve macrophages. J Leukoc Biol. (2006) 79:1181-92. doi: $10.1189 / \mathrm{jlb} .0405191$

195. Buhtoiarov IN, Sondel PM, Wigginton JM, Buhtoiarova TN, Yanke EM, Mahvi DA, et al. Anti-tumour synergy of cytotoxic chemotherapy and anti-CD40 plus CpG-ODN immunotherapy through repolarization of tumour-associated macrophages. Immunology. (2011) 132:226-39. doi: 10.1111/j.1365-2567.2010.03357.x

196. Relation T, Yi T, Guess AJ, La Perle K, Otsuru S, Hasgur S, et al. Intratumoral delivery of interferongamma-secreting mesenchymal stromal cells repolarizes tumor-associated macrophages and suppresses neuroblastoma proliferation in vivo. Stem Cells. (2018) 36:915-24. doi: 10.1002/stem.2801

197. Kock A, Larsson K, Bergqvist F, Eissler N, Elfman LHM, Raouf J, et al. Inhibition of microsomal prostaglandin E synthase-1 in cancer-associated fibroblasts suppresses neuroblastoma tumor growth. EBioMedicine. (2018) 32:84-92. doi: 10.1016/j.ebiom.2018.05.008
198. Komorowski M, Tisonczyk J, Kolakowska A, Drozdz R, Kozbor D. Modulation of the tumor microenvironment by CXCR4 antagonistarmed viral oncotherapy enhances the antitumor efficacy of dendritic cell vaccines against neuroblastoma in syngeneic mice. Viruses. (2018) 10:455. doi: $10.3390 / \mathrm{v} 10090455$

199. Teitz T, Stanke JJ, Federico S, Bradley CL, Brennan R, Zhang J, et al. Preclinical models for neuroblastoma: establishing a baseline for treatment. PLoS ONE. (2011) 6:e19133. doi: 10.1371/journal.pone. 0019133

200. Cekanova M, Rathore K. Animal models and therapeutic molecular targets of cancer: utility and limitations. Drug Des Devel Ther. (2014) 8:1911-21. doi: 10.2147/DDDT.S49584

201. Mak IW, Evaniew N, Ghert M. Lost in translation: animal models and clinical trials in cancer treatment. Am J Transl Res. (2014) 6:114-8.

202. Day CP, Merlino G, Van Dyke T. Preclinical mouse cancer models: a maze of opportunities and challenges. Cell. (2015) 163:39-53. doi: 10.1016/j.cell.2015.08.068

203. Braekeveldt N, Bexell D. Patient-derived xenografts as preclinical neuroblastoma models. Cell Tissue Res. (2018) 372:233-43. doi: $10.1007 / \mathrm{s} 00441-017-2687-8$

204. Rossa C Jr, D'silva NJ. Immune-relevant aspects of murine models of head and neck cancer. Oncogene. (2019) 38:3973-88. doi: 10.1038/s41388-019-0686-9

205. Weiss WA, Aldape K, Mohapatra G, Feuerstein BG, Bishop JM. Targeted expression of MYCN causes neuroblastoma in transgenic mice. EMBO J. (1997) 16:2985-95. doi: $10.1093 / \mathrm{emboj} / 16.11$. 2985

206. Heukamp LC, Thor T, Schramm A, De Preter K, Kumps C, De Wilde B, et al. Targeted expression of mutated ALK induces neuroblastoma in transgenic mice. Sci Transl Med. (2012) 4:141ra191. doi: 10.1126/scitranslmed. 3003967

207. Rasmuson A, Segerstrom L, Nethander M, Finnman J, Elfman LH, Javanmardi $\mathrm{N}$, et al. Tumor development, growth characteristics and spectrum of genetic aberrations in the TH-MYCN mouse model of neuroblastoma. PLoS ONE. (2012) 7:e51297. doi: 10.1371/journal.pone.0051297

208. Althoff K, Beckers A, Bell E, Nortmeyer M, Thor T, Sprussel A, et al. A Cre-conditional MYCN-driven neuroblastoma mouse model as an improved tool for preclinical studies. Oncogene. (2015) 34:3357-68. doi: 10.1038/onc.2014.269

209. Ornell KJ, Coburn JM. Developing preclinical models of neuroblastoma: driving therapeutic testing. BMC Biomed Eng. (2019) 1:33. doi: $10.1186 / s 42490-019-0034-8$

Conflict of Interest: The authors declare that the research was conducted in the absence of any commercial or financial relationships that could be construed as a potential conflict of interest.

Copyright () 2020 Liu and Joshi. This is an open-access article distributed under the terms of the Creative Commons Attribution License (CC BY). The use, distribution or reproduction in other forums is permitted, provided the original author(s) and the copyright owner(s) are credited and that the original publication in this journal is cited, in accordance with accepted academic practice. No use, distribution or reproduction is permitted which does not comply with these terms. 